\title{
Hierarchical $Y$ and USY zeolites designed by post-synthetic strategies
}

\section{Journal Article}

\section{Author(s):}

Verboekend, Danny; Vilé, Gianvito; Pérez-Ramírez, Javier

Publication date:

2012-03-07

Permanent link:

https://doi.org/10.3929/ethz-a-010786543

Rights / license:

In Copyright - Non-Commercial Use Permitted

Originally published in:

Advanced Functional Materials 22(5), https://doi.org/10.1002/adfm.201102411

\section{Funding acknowledgement:}

134572 - A fundamental approach to the scale up of hierarchical zeolite catalysts (SNF) 
DOI: $10.1002 /$ adfm.201102411

\section{FUNCANCEDAL \\ Submitted to}

\section{Hierarchical Y and USY zeolites designed by post-synthetic strategies}

By Danny Verboekend, Gianvito Vilé, and Javier Pérez-Ramírez*

[*] Prof. J. Pérez-Ramírez, D. Verboekend, G. Vilé

Institute for Chemical and Bioengineering, Department of Chemistry and Applied

Biosciences, ETH Zurich, Wolfgang-Pauli-Strasse 10, CH 8093, Zurich

(Switzerland)

E-mail: jpr@chem.ethz.ch

Keywords: Hierarchical zeolites, FAU, Post-synthetic strategies, Adsorption, Catalysis 


\section{Abstract}

Submitted to

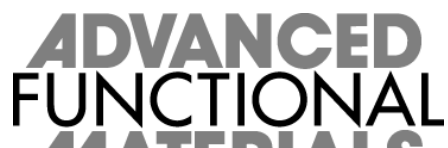

Strategic combinations of affordable and scalable post-synthetic modifications enabled to design a broad family of hierarchical Y and USY zeolites (FAU topology) independent on the $\mathrm{Si} / \mathrm{Al}$ ratio. Pristine $(\mathrm{Y}, \mathrm{Si} / \mathrm{Al}=2.4)$, steamed $(\mathrm{USY}, \mathrm{Si} / \mathrm{Al}=2.6)$, and steamed and dealuminated (USY, Si/Al = 15 and 30$)$ zeolites were exposed to a variety of acid $\left(\mathrm{H}_{4} \mathrm{EDTA}\right.$ and $\mathrm{Na}_{2} \mathrm{H}_{2}$ EDTA) and base treatments $(\mathrm{NaOH})$, which led to the introduction of mesopore surfaces up to $500 \mathrm{~m}^{2} \mathrm{~g}^{-1}$, while preserving the intrinsic zeolite properties. Pristine Y and USY zeolites ( $\mathrm{Si} / \mathrm{Al} \sim 2.5$ ) required mild dealumination (to $\mathrm{Si} / \mathrm{Al}>4$ in the case of $\mathrm{Y}$ ) to facilitate subsequent efficient desilication. Alkaline treatment of Y and USY zeolites with low Si/Al ratios ( 4-6) led to an abundance of Al-rich debris, which could be readily removed by a subsequent mild acid wash. On the other hand, severely steamed and dealuminated, hence Sirich, USY zeolites $(\mathrm{Si} / \mathrm{Al}=15$ and 30$)$ proved extremely sensitive to the alkaline solution, displaying facile dissolution and substantial amorphization. For the latter group of ultra-stable $\mathrm{Y}$ zeolites, the presence of $\mathrm{TPA}^{+}$in the alkaline solution enables to protect the zeolite structures upon the introduction of mesoporosity by desilication, preserving crystallinity and micropore volume. The sorption and catalytic properties of the hierarchical Y and USY zeolites were superior compared to the conventional counterparts. 


\section{Introduction}

Submitted to

Zeolite catalysts are of eminent importance in a number of chemical reactions associated with the (petro)chemical and oil refining industries, ${ }^{[1,2]}$ and raise substantial interest in new applications, such as the conversion of biomass into valuable chemicals. ${ }^{[3,4]}$ Nevertheless, especially during the processing of bulky molecules in the liquid phase, a sub-optimal utilization of the active sites present in zeolites is often implied by limited access and slow intra-crystalline diffusion in their micropores. ${ }^{[5]}$ In response to the need of improved catalytic processes, hierarchical (mesoporous) zeolites were conceived. These modified zeolites integrate the native microporosity with an auxiliary level of inter or intra-crystalline mesopores, increasing the external surface area substantially. This brings enhanced accessibility due to the increased number of pore mouths and shortened average diffusion pathlength in the micropores. ${ }^{[6-9]}$ The superior lab-scale performance of hierarchical zeolites compared to conventional counterparts in a wide range of catalyzed reactions is unquestionable.

Currently, a varied assortment of top-down and bottom-up approaches is available to synthesize hierarchically structured zeolites. ${ }^{[10-14]}$ The synthetic elegance of bottom-up methods is counteracted by a low chance for industrialization, since they commonly necessitate the use of costly and commercially unavailable reactants as mesopore-inducing agents, ${ }^{[15-19]}$ and/or lead to products not easily separated from the mother liquor, e.g. nanocrystals or nano-sheets. ${ }^{[19,20]}$ On the other hand, top-down approaches such as demetallation are highly effective and scalable at a reasonable cost. As a matter of fact, post-synthetic modifications are largely responsible for the success of zeolites in general, yielding superior catalysts in terms of stability, composition, and acid site speciation. ${ }^{[2]}$ The best example, applied in industry since the late 60 s, is the stabilization of Y zeolite by steam treatment, ${ }^{[21-24]}$ 
Submitted to

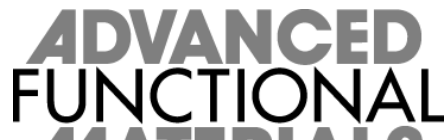

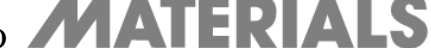

although acid treatments are routinely applied by zeolite producers to remove extraframework aluminum. ${ }^{[23,24]}$

Stabilization of the pristine $\mathrm{Y}$ zeolite (FAU topology $)^{[25]}$ by framework dealumination is commonly performed, since its high framework $\mathrm{Al}$ content renders it unstable once brought in the protonic from. The ultra-stable derivative (zeolite USY) is widely used in industry for fluid catalytic cracking and hydrocracking, ${ }^{[2,7]}$ and a generalized protocol to synthesize hierarchical analogues would be of prominent value because of the relatively bulky hydrocarbons involved and the need to control selectivity and to increase lifetime. The dealumination of the framework can, besides increasing (hydro)thermal stability, also lead to the introduction of a secondary network of mesopores in the zeolite crystal. $^{[7,24,26]}$ Nevertheless, in the case of steam treatment, the formed mesopores do not significantly affect intra-crystalline diffusion of probe molecules, ${ }^{[27]}$ since they are mostly present as cavities. ${ }^{[28]}$ In the last decade, base leaching, known as desilication, has become a widely-applied postsynthetic treatment, since it enables to introduce a network of connected intra-crystalline mesopores, while conserving the intrinsic zeolite properties. ${ }^{[14,29]}$ Desilication has been routinely applied to introduce a secondary network of mesopores in multiple high-silica frameworks in the $\mathrm{Si} / \mathrm{Al}$ range 10 to infinite. ${ }^{[14,30,31]}$ However, alkaline treatment on zeolites with high $\mathrm{Al}$ content $(\mathrm{Si} / \mathrm{Al}$ ratio $<10)$ remains relatively unexplored.

Two recent papers revealed the main challenges in the preparation of hierarchical $\mathrm{Y}$ and USY by desilication. Qin et al. ${ }^{[32]}$ performed severe alkaline treatments (368 K, 0.5-1.3 M $\mathrm{NaOH}, 1-3 \mathrm{~h}$ ) on a pristine zeolite $\mathrm{Y}$ (mesopore surface area $=18 \mathrm{~m}^{2} \mathrm{~g}^{-1}, \mathrm{Si} / \mathrm{Al}=3.1$ ), but obtained a limited mesoporosity $\left(S_{\text {meso }}=61 \mathrm{~m}^{2} \mathrm{~g}^{-1}\right)$, whereas crystallinity remained mostly unchanged. On the contrary, de Jong et al. ${ }^{[33]}$ performed alkaline treatments on a severely steamed and acid-leached zeolite USY $\left(S_{\text {meso }}=213 \mathrm{~m}^{2} \mathrm{~g}^{-1}, \mathrm{Si} / \mathrm{Al}=28\right)$. They used extremely mild conditions (298 K, 0.05-0.1 M NaOH, $15 \mathrm{~min}$ ) to develop impressive external surfaces 


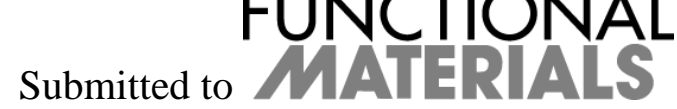

up to $443 \mathrm{~m}^{2} \mathrm{~g}^{-1}$. However, a negative effect of alkaline treatment was that the zeolite displayed a strong amorphization, substantiated by the two-third reduction in micropore volume (from $0.21 \mathrm{~cm}^{3} \mathrm{~g}^{-1}$ down to $0.07 \mathrm{~cm}^{3} \mathrm{~g}^{-1}$ ) and crystallinity. Although these works clearly prove that $\mathrm{Y}$ and severely-steamed and dealuminated USY behave very distinctly in alkaline media, no general knowledge for the precise manipulation of the FAU framework exists thus far.

Herein, we present strategic combinations of acid and base treatments to design hierarchical Y and USY zeolites. The selection of different starting zeolites combined with a comprehensive set of post-synthetic modifications enabled to substantiate the contradictory relationship between the sensitive FAU framework and its high $\mathrm{Al}$ content. We identify a critical Si/Al ratio above which the facile dissolution by alkaline treatment and introduction of external surface occurs. Besides, we highlight the necessity to remove debris from zeolites after acid or alkaline treatment to fully exploit the intrinsic and the newly developed properties in adsorption and/or catalysis. In the case of severely dealuminated USY zeolites, it is demonstrated that the inclusion of tetraalkalyammonium cations in the base solution enables to introduce substantial mesoporosity, while maintaining the intrinsic zeolite properties. The superiority of hierarchical Y and USY is evidenced in the adsorption of toluene, the alkylation of benzyl alcohol with toluene, and the pyrolysis of polyethylene. In an exciting culmination to recent studies on MFI, this work extrapolates gained insights to the FAU framework, and provides novel post-synthetic strategies to the synthesis of superior mesoporous zeolites.

\section{Results and discussion}

The commercial zeolites used as starting materials for the post-synthetic treatments comprised a parent $\mathrm{Y}(\mathrm{Si} / \mathrm{Al}=2.4)$, a steamed USY $(\mathrm{Si} / \mathrm{Al}=2.6)$, and two severely steamed and dealuminated USY zeolites $(\mathrm{Si} / \mathrm{Al}=15$ and 30$)$. Acid treatments performed comprised 
Submitted to

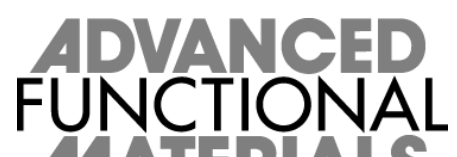

aqueous solutions of ethylenediaminetetraacetic acid ( $\mathrm{H}_{4}$ EDTA) and ethylenediaminetetraacetic acid disodium salt $\left(\mathrm{Na}_{2} \mathrm{H}_{2} \mathrm{EDTA}\right)$, whereas base treatments were performed using aqueous $\mathrm{NaOH}$ in the absence or presence of tetrapropylammonium cations $\left(\mathrm{TPA}^{+}\right)$. The majority of the study focuses on $\mathrm{Y}$ zeolite $(\mathrm{Si} / \mathrm{Al}=2.4)$, which is described in Sections 2.1-2.5. Results derived from treatments of the USY zeolites are described in Section 2.6. A general discussion on strategies to design hierarchical Y and USY zeolites is provided in Section 2.7.

\subsection{Individual acid and base treatments on zeolite $Y$}

The parent sample $(\mathrm{P}, \mathrm{Si} / \mathrm{Al}=2.4)$ comprised octahedron-type crystals typical for the faujasite zeolite. ${ }^{[28]}$ TEM showed that the crystals were free of intra-crystalline defects (Fig. 1), while its X-ray diffraction (XRD) pattern revealed a highly crystalline faujasite in the absence of impurities (Fig. SI1). $\mathrm{N}_{2}$ adsorption resulted in a type-I isotherm, typical for purely microporous materials (P in Fig. 2). Application of the $t$-plot model evidenced a micropore volume ( $\left.V_{\text {micro }}\right)$ of $0.30 \mathrm{~cm}^{3} \mathrm{~g}^{-1}$ and a limited mesopore surface area $\left(S_{\text {meso }}\right)$ of $22 \mathrm{~m}^{2} \mathrm{~g}^{-1}$.

Various (individual and sequential) treatments are presented in this paper, ultimately aimed at preparing a superior hierarchical Y zeolite. Naturally, the individual influence of each treatment on the parent zeolite $\mathrm{Y}$ was explored (Fig. 3). The treatment conditions of representative samples are provided in Table 1, whereas a full overview of the treatment conditions and the textural properties of the resulting solids is shown in Tables SI1-2.

In line with the low $\mathrm{Si} / \mathrm{Al}$ ratio of the pristine zeolite, relatively high molarities of aqueous $\mathrm{NaOH}$ were required to induce dissolution (Fig. 3a). Accordingly, only at $5 \mathrm{~m} \mathrm{NaOH}$, yields dropped to $c a .60 \%$, i.e. a value typical for alkaline-treated MFI zeolites. ${ }^{[31]}$ As expected, ${ }^{[32]}$ the alkaline treatments of pristine $\mathrm{Y}$ resulted in a minor development of mesoporosity; the highest $S_{\text {meso }}$ did not exceed $60 \mathrm{~m}^{2} \mathrm{~g}^{-1}$. Additionally, the $\mathrm{N}_{2}$ isotherm suggests the presence of macroporosity (Fig. 2), which was confirmed by TEM (AT4 in Fig. 1). On the other hand, crystallinity remained relatively high (ca. 80\%), while $V_{\text {micro }}$ remained mostly unchanged. It is 
Submitted to

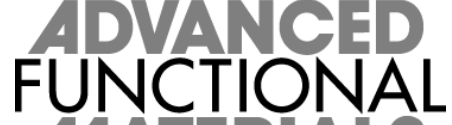

likely that the high alkalinities applied led to an unselective dissolution, incapable of directing dissolution towards efficient introduction of intra-crystalline mesoporosity.

Aqueous solutions of $\mathrm{H}_{4}$ EDTA were used to dealuminate the $\mathrm{Y}$ framework since, compared to mineral acids, it preserves crystallinity to a larger extent. ${ }^{[26]}$ Exposure to aqueous $\mathrm{H}_{4}$ EDTA solutions led to a gradual loss in yields (down to $70 \%$ at $0.2 \mathrm{M}$ ), while crystallinity reduced strongly (down to $c a$. $20 \%$ at $0.2 \mathrm{M}$, Fig. $3 \mathbf{b}$ ). The latter is unsurprising since at $0.2 \mathrm{M}$ EDTA, more than $50 \%$ of $\mathrm{Al}$ should have been removed from the solid. ${ }^{[34]}$ Even though the framework appeared substantially affected, application of the t-plot model to the isotherm did not reveal the loss of micropore volume or the presence of mesopores. However, closer inspection of a representative $\mathrm{N}_{2}$ isotherm (DA2 in Fig. 2) suggested the presence of large micropores or small mesopores. The drop in micropore volume became significant at concentrations exceeding $0.11 \mathrm{M}$ (down to $\mathrm{ca} .0 .12 \mathrm{~cm}^{3} \mathrm{~g}^{-1}$ at $0.20 \mathrm{M}$ ).

Treatment with aqueous $\mathrm{Na}_{2} \mathrm{H}_{2}$ EDTA is commonly used to remove extra-framework $\mathrm{Al}$ from steamed USY zeolites. ${ }^{[2,35]}$ It should therefore ideally exert a minor influence on the parent crystals. Fig. 3c shows that the yields remained fairly high (ca. 90\%), even when concentrations up to $0.6 \mathrm{M}$ were employed (Table SI2). On the other hand, crystallinity increased to a fictitious 104\%, which suggests the removal of some amorphous species. The porous properties of the $\mathrm{Na}_{2} \mathrm{H}_{2}$ EDTA-treated samples corroborated the minor influence of the treatment on the parent zeolite. Accordingly, a representative isotherm revealed a similar trend to that of P (e.g. sample AW1 in Fig. 2). The vertical shift of the isotherm is attributed to the ion exchange taking place during treatment, i.e. $\mathrm{Na}^{+}$or $\mathrm{H}^{+}$ions taking the place of the bulkier $\mathrm{NH}_{4}{ }^{+}$ions in the micropores. 


\subsection{Sequential acid and base treatments on zeolite $\mathbf{Y}$}

Submitted to

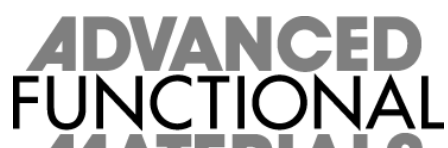

Individual post-synthetic treatments did not succeed in introducing substantial mesoporosity in parent Y zeolite. An alternative strategy to obtain highly mesoporous Y zeolites concerns the application of sequential alkaline and acid treatments. ${ }^{[31]}$ Hereto the alkaline-treated sample AT4 was washed with $\mathrm{Na}_{2} \mathrm{H}_{2}$ EDTA to obtain AT4-AW1. These efforts however, did not result into substantial mesoporosity (Table SI3), and confirmed that alkaline treatment alone is not suited to introduce mesoporosity in the pristine Y zeolite.

To study the influence of dealumination prior to desilication, sequential $\mathrm{H}_{4}$ EDTA and $\mathrm{NaOH}$ treatments were systematically screened. This approach resulted in an extended matrix of solids, a large number of which being hierarchical porous structures (Table SI4). For clarity, the influence of the sequential treatments on the porous properties is illustrated by the $\mathrm{N}_{2}$ isotherms of representative hierarchical zeolites DA1-AT1 and DA2-AT2 (Fig. 4a-b), and the general trends are discussed in more detail for DA2-AT2. The $\mathrm{N}_{2}$ isotherm of the latter sample displayed a similar uptake at low relative pressures compared to sample P, which was coupled to an increased uptake at middle-to-high relative pressures. This amounted to a large mesopore surface $\left(330 \mathrm{~m}^{2} \mathrm{~g}^{-1}\right)$ coupled to a microporosity of $0.20 \mathrm{~cm}^{3} \mathrm{~g}^{-1}$ (Table 2). Compared to DA2, this represents an 8-fold increase of the external surface area and a the preservation of two-thirds of the micropore volume. The derived mesopore size distribution displayed mesopores centered around $8 \mathrm{~nm}$, whereas contributions at higher mesopores sizes were completely absent. The latter suggests that purely intra-crystalline mesopores were formed, which was confirmed by TEM (DA2-AT2 in Fig. 1). Surprisingly, although substantial mesoporosity was introduced, crystallinity did not decrease strongly upon alkaline treatment (from $31 \%$ to $18 \%$, Fig. 5).

The textural parameters collected in Table SI4 were plotted in a number of contour plots to facilitate interpretation. Fig. 6a shows the overall weight loss upon sequential $\mathrm{H}_{4}$ EDTA and 
Submitted to

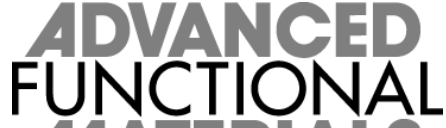

$\mathrm{NaOH}$ treatment. The $\mathrm{H}_{4}$ EDTA-treated zeolites (prior to desilication) are represented on the $y$-axis, whereas the $x$-axis depicts the zeolites treated in $\mathrm{NaOH}$ only. In agreement with Fig. 3, yields remained $c a$. $100 \%$ on the $x$-axis, whereas on the $y$-axis yields decreased to $c a$. $80 \%$. Upon alkaline treatment of the dealuminated zeolites, yields lowered substantially starting from a $\mathrm{H}_{4}$ EDTA molarity $>0.07 \mathrm{M}$. Since mesopores are typically generated by the partial dissolution of the zeolite, this implies that, to introduce substantial mesoporosity in Y zeolites, a Si/Al ratio of roughly 4 needs to be attained. Possibly, the same ratio needs to be reached to enable the recrystallization process as claimed in ref. 36. In the latter patent, a dealumination step using citric acid was required prior to successful alkaline-induced recrystallization. Table SI5 shows that exactly this treatment led to the same yield as DA2 (87\%), and concomitant alkaline treatment enabled significant dissolution of the material.

In line with the dissolution pattern, Fig. $\mathbf{6 b}$ shows that mesopore surface areas exceeding $150 \mathrm{~m}^{2} \mathrm{~g}^{-1}$ were obtained starting from $\mathrm{Y}$ zeolites dealuminated using $\mathrm{H}_{4}$ EDTA concentrations $>0.07 \mathrm{M}$. Moreover, the plot illustrates that the highest mesopore surface areas were obtained in the range of $0.1-0.4 \mathrm{M}$ of $\mathrm{NaOH}$. Compared to alkaline treatment on ZSM$5,{ }^{[31]}$ the mesopore surface areas were attained at relatively high overall yields. The latter is tentatively explained by the relatively low-framework density of FAU (13.3 T atoms $\mathrm{nm}^{-3}$ ) compared to MFI (18.4 $\mathrm{T}$ atoms $\left.\mathrm{nm}^{-3}\right),{ }^{[25]}$ requiring the removal of less atoms to obtain a similar-sized mesopore.

High micropore volumes of $c a .0 .30 \mathrm{~cm}^{3} \mathrm{~g}^{-1}$ were obtained over a wide variety of conditions (Fig. 6c). In fact, the reduction of the micropore volume depended mostly on the applied $\mathrm{H}_{4}$ EDTA concentration. Accordingly, marked reductions become apparent only after dealumination with conditions $>0.11 \mathrm{M} \mathrm{H}$ EDTA. The applied alkaline treatment did not affect the obtained values, a somewhat counterintuitive result taking our previous work on Alrich MFI zeolites into account. ${ }^{[31]}$ 
Submitted to 14 A

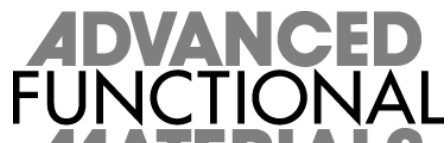

Additional efforts, regarding sequential acid and base treatment with aqueous $\mathrm{HCl}$ as dealumination agent, proved the value of the $\mathrm{H}_{4}$ EDTA treatment. In the cases $\mathrm{HCl}$ was used, the obtained solids exhibited substantial degrees of mesoporosity (up to $234 \mathrm{~m}^{2} \mathrm{~g}^{-1}$ ), but the micropore volume reduced to zero (Table SI5). The strong reduction of the micropore volume corroborates the more destructive of $\mathrm{HCl}$ treatment over that of $\mathrm{H}_{4}$ EDTA during dealumination of Y zeolites. ${ }^{[26]}$

The porosities of the sequentially-treated solids enabled accurate estimation of the average mesopore diameter. Fig. 6d shows a variety of pores in the range of ca. 2 to $20 \mathrm{~nm}$ as a function of $\mathrm{H}_{4}$ EDTA and $\mathrm{NaOH}$ concentration. It proved that the highest mesopore surface areas were obtained at pore sizes around $8 \mathrm{~nm}$. When the mesopore size further increased, the mesoporosity dropped, while the total pore volumes remained constant around a substantial $0.55 \mathrm{~cm}^{3} \mathrm{~g}^{-1}$ (Table SI4). Fig. 7 highlights the relation between the mesopore diameter and the mesopore surface area for zeolites dealuminated at $0.07 \mathrm{M}$ and $0.11 \mathrm{M} \mathrm{H} \mathrm{H}_{4}$ EDTA. A volcano plot is obtained with a maximum $S_{\text {meso }}$ at $8 \mathrm{~nm}$, displaying a clear relation between the mesopore size and the external surface.

\subsection{Removal Al-rich debris from alkaline-treated Y zeolites}

The removal of Al-rich debris from alkaline-treated medium-pore zeolites by subsequent acid treatment demonstrated of high value for ZSM-5, ${ }^{[31,37]}$ ferrierite, ${ }^{[38]} \mathrm{ZSM}-22,{ }^{[39,40]}$ and theta-1. ${ }^{[41]}$ Reported benefits after the subsequent acid treatment include an enhanced microand mesoporosity, increased crystallinity, restored acidity and composition, and, ultimately, enhanced catalytic activity. ${ }^{[31,37-41]}$ The acid washing step was optimized using various concentrations of $\mathrm{Na}_{2} \mathrm{H}_{2}$ EDTA on a number of sequentially acid and base-treated zeolites (Table SI3). For sake of conciseness, discussion is centralized on the results using the 
Submitted to

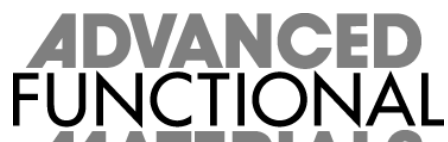

14 A ERIAS

treatment of $0.11 \mathrm{M} \mathrm{Na}_{2} \mathrm{H}_{2}$ EDTA (AW1) on the sequentially acid and alkaline-treated samples (DAx-ATx).

Upon $\mathrm{Na}_{2} \mathrm{H}_{2}$ EDTA treatment of the dealuminated and desilicated solids, yields reduced with both the severity of the alkaline treatment as the preceding acid treatment (Table 2). Unlike in the case of the samples that were only alkaline-treated before washing, the influence of the $\mathrm{Na}_{2} \mathrm{H}_{2}$ EDTA treatment on the physico-chemical properties was more evident. In line with the removal of amorphous Al-rich debris, the crystallinity of DA2-AT2 increased from 18\% to 35\% (DA2-AT2-AW1, Fig. 5). The nitrogen isotherms of the washed samples show that the uptake at $p / p_{0}<0.1$, as well as at middle-to-high relative pressures, increased markedly (Fig. 4). In line with our previous work, ${ }^{[31]}$ the mild acid treatment resulted in the clearing of porosity, leading to increased pore volumes (Table 2). For example, upon washing of DA2-AT2, $V_{\text {pore }}$ increased from $0.66 \mathrm{~cm}^{3} \mathrm{~g}^{-1}$ to $0.79 \mathrm{~cm}^{3} \mathrm{~g}^{-1}$ (DA2-AT2-AW1). Additionally, the washing increased the average mesopore size distributions distinctly from 8 to $10 \mathrm{~nm}$ (DA2-AT2-AW1), which was confirmed by TEM (DA2-AT2 and DA2-AT2-AW1 in Fig. 1). In the case of the solids featuring mesopores of $2 \mathrm{~nm}$ (DA1-AT1, and DA2-AT1), the $\mathrm{Na}_{2} \mathrm{H}_{2}$ EDTA treatment resulted in average mesopore sizes of $3 \mathrm{~nm}$ (DA1-AT1-AW1), and $4 \mathrm{~nm}$ (DA2-AT1-AW1). Except for DA2-AT2-AW1, the external surface area of the samples increased (Table 2). Strikingly, including DA2-AT2-AW1, the relation between the mesopore size and the total surface area, as discussed in Section 2.2, holds solidly after the final acid washing (Fig. 7).

Recently, the desilication efficiency was introduced as a tool to examine the loss of solids upon introduction of mesoporosity by post-synthetic modification. ${ }^{[40]}$ In this work the desilication efficiencies of the washed samples varied between 5 and $7 \mathrm{~m}^{2} \mathrm{~g}^{-1} \%^{-1}$, which is slightly higher than those for ZSM-5, and should be due to the relatively high overall yields. 
Submitted to

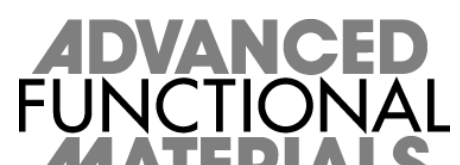

The scale up of the preparation of mesoporous zeolites by desilication has been demonstrated multiple-liter scale, ${ }^{[42]}$ and more recently on the cubic meter scale. ${ }^{[43]}$ However, these works concerned only a single alkaline treatment on MFI zeolites. In an assessment of reproducibility, we have successfully scaled up all 3 sequential treatments by a factor of roughly 50. Table SI6 shows samples required to prepare sample DA7-AT1-AW1 starting from either 5 or $100 \mathrm{~g}$ of parent Y zeolite. Independent on the scale of the various treatments, yields and the resulting porosities are highly comparable, revealing the remarkable scalability of the preparation of mesoporous zeolites by post-synthetic modifications.

\subsection{Structure, porosity, and morphology of Y zeolites}

For the acidity studies and catalytic evaluation (described in Section 2.5), samples required transformation to the protonic form. It is known that ex situ protonation of zeolites can lead to the partial collapse of $\mathrm{Y}$ zeolites due to readsorption of water. ${ }^{[26]}$ We have nevertheless employed the latter approach since our catalytic application prevented to do so otherwise. Since samples that were treated at longer dealumination times (24 or $72 \mathrm{~h}$ ) exhibited a greater stability upon thermal activation (Fig. SI2), we selected sample DA4 (treated for 72 h) for further study.

The sequential treatments (DA4, AT1, and AW1) resulted in similar yields compared to what was described in previous sections (Table 2). Dealumination led to a substantial reduction (55\%) of the crystallinity, but not as pronounced as for DA2 (Fig. 5). Table 2 shows that, as can be alluded from ref. 34, the Si/Al ratio of 2.4 (P) increased to 5.5 (DA4), implying that about half of the $\mathrm{Al}$ was removed from the sample. A subtle difference of the porous properties of DA4 compared to DA2 was revealed by the $\mathrm{N}_{2}$ isotherm (Fig. 4). The uptake at $0.1<p / p_{0}<0.3$ was more pronounced, suggesting the presence of small mesopores, which were also noticeable in the mesopore size distributions. This difference is attributed to 
Submitted to

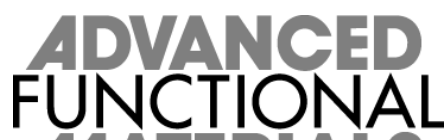

the prolonged reaction time, enabling a more thorough healing of the crystal through $\mathrm{Si}$ migration. ${ }^{[4]}$ TEM showed that DA4 did not possess the homogeneity evidenced by the parent zeolite, but the existence of small mesopores could not be ascertained (DA4 in Fig. 1). Upon acid wash of the dealuminated sample (to yield sample DA4-AW1), much like after the alkaline treatment, significant mesoporosity was formed $\left(S_{\text {meso }}=173 \mathrm{~m}^{2} \mathrm{~g}^{-1}\right)$. However, transmission electron microscopy suggested that the porosity is not as homogeneously distributed (DA4-AW1 in Fig. 1) and crystallinity decreased from 45\% to 31\% (Table 2).

Upon desilication of DA4, resulting in DA4-AT1, crystallinity reduced slightly down to $37 \%$, confirming the minimal influence of the alkaline-treatment on the zeolite structure. The $\mathrm{Si} / \mathrm{Al}$ ratio reduced to 3.9, ratifying the preferential extraction of $\mathrm{Si}$ from the solid. Moreover, Fig. 4 reveals that the uptake is shifted to higher relative pressures, indicative of larger mesopores. Accordingly, the mesopore size distribution shows an average mesopore size around $3 \mathrm{~nm}$, and an $S_{\text {meso }}$ of $177 \mathrm{~m}^{2} \mathrm{~g}^{-1}$ is obtained (Table 2). TEM clearly demonstrated the presence of intra-crystalline mesoporosity (DA4-AT1 in Fig. 1). The following mild acid washing (DA4-AT1-AW1) resulted in the removal of Al-rich debris, as was substantiated by the increased Si/Al ratio (to 4.2), crystallinity (to 52\%), and mesopore size (to $6 \mathrm{~nm}$ ). The increase in mesopore size was corroborated by TEM (DA4-AT1-AW1 in Fig. 1). The mesoporosity increased to $292 \mathrm{~m}^{2} \mathrm{~g}^{-1}$, which was coupled to a micropore volume of $0.26 \mathrm{~cm}^{3} \mathrm{~g}^{-1}$. We conclude that the dealumination treatment leads a partially defective crystal comprising small mesopores clogged with amorphous aluminosilicate debris. The removal of these species is most efficient applying first an alkaline treatment followed by treatment with a mild acid wash. This preferential order could be related to the realumination process that occurs upon alkaline treatment, leading to the reinsertion of $\mathrm{Al}$ in the framework. ${ }^{[45,46]} \mathrm{We}$ attribute the minimal drop of crystallinity upon alkaline treatment to both the removal of amorphous Si debris and the removal of Si from the framework. It should be emphasized that, 
Submitted to

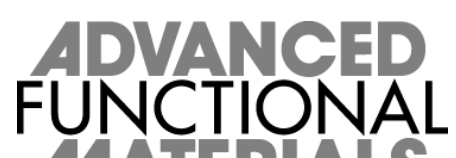

in general, the sequential alkaline treatment-acid wash provides a suitable tool to remove aluminosilicate debris from zeolites.

Hg porosimetry was measured on P and DA4-AT1-AW1 to monitor the influence on the accessibility of the porous structure (Fig. SI3). Compared to P, the recorded intrusion curve of DA4-AT1-AW1 revealed a strongly enhanced uptake at pressures around 10 bar, which is attributed to a more accessible inter-crystalline porosity. ${ }^{[4]}$ The latter is tentatively explained by a partial deagglomeration of the particles. However, further studies, e.g. complementary microscopic techniques, are required to ascertain this. On the other hand, whereas the parent zeolite did not display uptake at $P>10$ bar, the hierarchical zeolite showed enhanced uptake in the 1000-5000 bar pressure range, indicative of the presence of connected intra-crystalline mesopores. These measurements confirm the mesopore size determined by $\mathrm{N}_{2}$ adsorption and further emphasize the porous superiority of the hierarchical Y zeolite.

\subsection{Acidity, adsorption, and catalytic evaluation of $\mathbf{Y}$ zeolites}

Conversion to the protonic form by thermal activation led to the partial amorphization of the solids (Table SI7). The drop in crystallinity was about $40 \%$ for all samples. Nevertheless, the porous properties remained largely intact. The mesoporous sample of highest interest (DA4AT1-AW1) displayed a reduction in micropore volume from $0.26 \mathrm{~cm}^{3} \mathrm{~g}^{-1}$ to $0.19 \mathrm{~cm}^{3} \mathrm{~g}^{-1}$, whereas the mesopore surface area reduced from 292 to $202 \mathrm{~m}^{2} \mathrm{~g}^{-1} \cdot{ }^{27} \mathrm{Al}$ MAS NMR revealed that in all calcined samples, the majority of $\mathrm{Al}$ was present in a tetrahedral coordination (Fig. SI4).

Acidity assessment was performed by infrared spectroscopy performed in the $\mathrm{OH}$ stretching region (Fig. 8) and by temperature programmed desorption of ammonia (Fig. SI5). IR spectroscopy was undertaken the study the hydroxyls related to Brønsted acidity (3600 and $\left.3550 \mathrm{~cm}^{-1}\right)$ and those representative of isolated silanols on the external surface $\left(3740 \mathrm{~cm}^{-1}\right) .{ }^{[48]}$ 
Submitted to

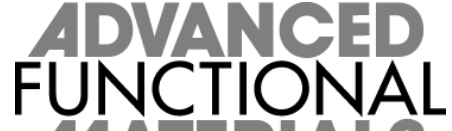

The parent Y zeolite displayed mainly the bands related to Brønsted acidity, attending to its high acidity and limited external surface area. Upon dealumination (DA4-H) the bands related to the Brønsted acidity became less intense, which should be related to the lower Al content and the formation of Al-rich debris, respectively. On the other hand, the band at $3740 \mathrm{~cm}^{-1}$ became prominent, corroborating the presence of substantial defects. Sequential alkaline treatment (DA4-AT1-H) led to a strong reduction in intensity and definition of the three bands. The latter relates to the realumination of the surface, ${ }^{[49]}$ which was also observed upon alkaline treatment of Al-rich MFI zeolites. ${ }^{[31]}$ Upon subsequent acid wash (DA4-AT1-AW1$\mathrm{H})$, the intensity and definition of all bands increased strongly again, attending to the removal of Al-rich debris, confirming the strong suppressive effect on the bands in the $\mathrm{OH}$ stretching region. Using $\mathrm{NH}_{3}$-TPD a more conclusive idea of the bulk acidity was provided (Fig. SI5). The total acidity of the samples, as estimated from the integral of the curves, related well to their $\mathrm{Al}$ content. It is clear that these samples deserve more in-depth acidic characterization by, for example, infrared spectroscopy of adsorbed CO and alkyl pyridines. These studies, however, are beyond the scope of this contribution.

Gravimetric adsorption of toluene was performed to examine the sorptive properties of the hierarchical Y zeolites in more detail (Fig. 9). Toluene sorption is particularly relevant since this molecule is an important reagent or product in numerous chemical reactions, e.g. alkylations. ${ }^{[2]}$ In line with the mostly microporous character of unmodified Y zeolites, the parent sample (P-Na) displayed a major uptake at low relative pressures, while uptake at higher relative pressures was mostly absent. The total uptake of toluene was ca. $2.5 \mathrm{mmol} \mathrm{g}{ }^{-1}$. The hierarchical sample in sodium form (DA4-AT1-AW1-Na) displayed an uptake of ca. $1.5 \mathrm{mmol} \mathrm{g}^{-1}$ at $p / p_{0}<0.1$, and an additional $2 \mathrm{mmol} \mathrm{g}^{-1}$ at higher relative pressures due to the presence of intra-crystalline mesopores. The total uptake was ca. $3.5 \mathrm{mmol} \mathrm{g}^{-1}$, i.e. $70 \%$ higher than that of P-Na, confirming the superior porous properties of the hierarchical zeolite. 
Submitted to 14 A

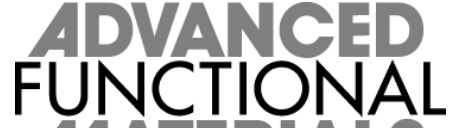

Catalytic evaluation was performed by the liquid-phase alkylation of benzyl alcohol with toluene. This reaction benefited dramatically from the introduction of mesoporosity by desilication in the case of ZSM-5. ${ }^{[31]}$ However, since the FAU micropores are, for toluene and benzyl alcohol, more accessible than the ZSM-5 micropores, it is the question whether the catalytic performance of the already very active $\mathrm{Y}$ zeolite is improved by the post-synthetic modifications. Fig. 10a shows the catalytic conversion as a function of time for selected zeolites. The performance of the parent zeolite (P-H) displayed a $47 \%$ conversion of benzylalcohol $\left(X_{\mathrm{BA}}\right)$ after $40 \mathrm{~min}$. Upon introduction of mesoporosity by sequential dealumination and desilication (DA4-AT1-H), a slightly higher activity was achieved $\left(X_{\mathrm{BA}}=\right.$ 53\% after $40 \mathrm{~min}$ ). Conversely, after the final wash (DA4-AT1-AW1-H), the activity almost doubled after 40 min of reaction ( $X_{\mathrm{BA}}=84 \%$ after $40 \mathrm{~min}$ ). Upon normalizing the conversion to the $\mathrm{Al}$ content, the differences between the samples became even more obvious. The activity of DA4-AT1-AW1-H was almost four-fold of that of P-H, and over two times that of DA4-AT1-AW1-H. This result highlights the superiority of the mesoporous zeolites and further stresses the essential role that the acid wash plays in the preparation of hierarchical Y zeolites. We attribute the improved catalytic activity to the improved access to the acid sites provided by the introduced secondary porosity. It can be concluded that the introduction external surface area is mostly efficient if accessible, hence connected to the external surface, and free of non-zeolitic debris.

\subsection{Hierarchical USY zeolites}

USY: In Sections 2.1-2.3 the introduction of mesoporosity in a pristine Y zeolite was tackled. However, it is unclear if the followed approach also holds for a Y zeolite that was steamed, i.e. a USY faujasite with similar bulk $\mathrm{Si} / \mathrm{Al}$ ratio but higher framework $\mathrm{Si} / \mathrm{Al}$ ratio. We performed alkaline treatments on a steamed zeolite (USY1-P) using different $\mathrm{NaOH}$ concentrations. The 
Submitted to 14 A

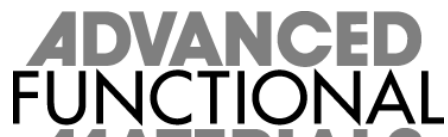

results, listed in Table 3, indicate that, like in the case of the pristine Y zeolite, relatively mild treatments (0.2 M NaOH, USY1-AT2) do not lead to any apparent modification of the solid. Only at higher concentrations ( $>1 \mathrm{M} \mathrm{NaOH}$ ) dissolution occurred, displaying yields down to 17\% (USY1-AT4). Upon treatment of USY1 at higher alkalinities, microporosity reduced drastically. The latter is attributed to the realumination of the extra-framework $\mathrm{Al}$ (generated by steaming) upon alkaline treatment. This suggests that the direct desilication of USY is not the right strategy.

To successfully introduce intra-crystalline mesoporosity, we applied the protocol established for the pristine Y zeolite on USY1-P. The resulting solid (USY1-DA3-AT1-AW1) displayed an impressive mesopore surface area $\left(296 \mathrm{~m}^{2} \mathrm{~g}^{-1}\right)$, and a micropore volume of 0.13 $\mathrm{cm}^{3} \mathrm{~g}^{-1}$ (Table 3). Accordingly, it is clear that, like in the case of pristine $\mathrm{Y}$, steamed zeolites are also readily prepared in hierarchical form by desilication once the $\mathrm{Si} / \mathrm{Al}$ ratio has been increased by mild dealumination. However, despite the large external surface increase, both acid treatments (DA3 and AW1) led to a reduction of the micropore volume. Additionally, although the mesopore surface area and the pore volume increased, the crystallinity of USY1DA3-AT1-AW1 was similar to that of USY1-DA3-AT1. The latter suggests that the applied acid treatments require further optimization, which should be due to the different nature of aluminum in the steamed zeolite.

Dealuminated USY: A remarkable result is the large difference in dissolution kinetics of pristine and dealuminated Y zeolite upon alkaline treatment. As mentioned in the Introduction, the facile dissolution is particularly pronounced for zeolites which were severely dealuminated. The high sensitivity of the FAU topology to alkaline media should relate to the relative low framework density, high surface area, and large micropores (all of which are tightly interconnected). ${ }^{[25]}$ Of course, whereas the application of mild conditions is 
Submitted to
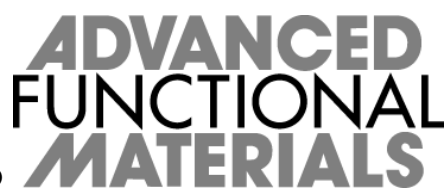

economically and environmentally favorable, the associated amorphization of the material, as evidenced by de Jong et al. ${ }^{[33]}$, is undesired.

Recently, we demonstrated that inclusion of tetraalkylammonium cations in the alkaline solution protects the zeolite crystals during the demetallation process. ${ }^{[50]}$ Using this concept, we executed alkaline treatments on steamed and severely dealuminated USY zeolites $(\mathrm{Si} / \mathrm{Al}=15$, coded 'USY2-P' and $\mathrm{Si} / \mathrm{Al}=30$, coded 'USY3-P') in the absence and in the presence of $\mathrm{TPA}^{+}$. Fig. 11a shows that, upon conventional alkaline treatment of USY2, the $\mathrm{N}_{2}$-isotherm displayed increased uptake at middle-to-high relative pressures and mesopore surface areas up to $275 \mathrm{~m}^{2} \mathrm{~g}^{-1}$ were obtained (USY2-AT1, Table 3). However, the uptake at $p / p_{0}<0.1$ decreases strongly, indicating a significant amorphization of the material. Indeed, $V_{\text {micro }}$ dropped from $0.28 \mathrm{~cm}^{3} \mathrm{~g}^{-1}$ (USY1-P) down to $0.10 \mathrm{~cm}^{3} \mathrm{~g}^{-1}$ (USYY2-AT1). In line with previous observations, ${ }^{[33]}$ the $65 \%$ loss of micropore volume was accompanied with a similar loss in crystallinity (62\%, Table 3). The more amorphous appearance of the crystals was confirmed by TEM (Fig. 11b).

When $\mathrm{TPA}^{+}$was included in the alkaline solution, the resulting solids showed dramatically improved structural and textural properties. Sample USY2-AT2+TPA displayed a similar uptake at $p / p_{0}>0.1$ compared to USY2-AT1, but the uptake at low relative pressures was fully preserved with respect to USY2-P (Fig. 11a). Accordingly, the textural properties indicate a $V_{\text {micro }}$ of $0.29 \mathrm{~cm}^{3} \mathrm{~g}^{-1}$ and a $S_{\text {meso }}$ of $253 \mathrm{~m}^{2} \mathrm{~g}^{-1}$. Moreover, the crystallinity loss upon treatment was limited to 37\% (Table 3).

When the same treatments were applied to USY3, the positive influence of $\mathrm{TPA}^{+}$in the alkaline solution was even more striking. The solids exposed to the standard desilication protocol combined the development of external surface area (up to $321 \mathrm{~m}^{2} \mathrm{~g}^{-1}$ for USY3-AT2) with a drastic loss of the micropore volume (0 for USY3-AT2). In contrast, when TPA ${ }^{+}$ cations were present in the alkaline solution, $V_{\text {micro }}$ remained mostly unaffected, while 
Submitted to

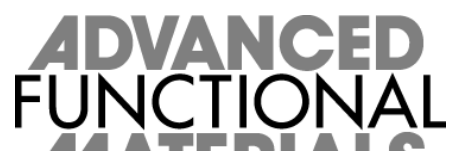

MATERIALS

strongly enhanced $V_{\text {pore }}$ (up to $1.10 \mathrm{~cm}^{3} \mathrm{~g}^{-1}$ for USY3-AT2+TPA) and $S_{\text {meso }}$ (up to $500 \mathrm{~m}^{2} \mathrm{~g}^{-1}$ for USY3-AT2+TPA) were attained (Fig. 11c, Table 3). Undoubtedly, the protective role displayed on $\mathrm{MF}^{[30,50]}$ is also effective, if not more effective, for FAU. Therefore, the use of pore-growth moderators in desilication should be particularly efficient for framework comprising large micropores and/or large surface areas.

Adsorption and catalytic evaluation: Gravimetric adsorption of toluene was also performed on USY2-P and USY2-AT2+TPA (Fig. 9). At low relative pressures ( $\left.p / p_{0}<0.1\right)$, USY2-P displayed an uptake of $c a .2 \mathrm{mmol} \mathrm{g}^{-1}$, which was combined with an additional uptake of $1.5 \mathrm{mmol} \mathrm{g}^{-1}$ at higher relative pressures. The latter relates to the microporous nature of the zeolite and the presence mesoporosity $\left(S_{\text {meso }}=125 \mathrm{~m}^{2} \mathrm{~g}^{-1}\right)$. The isotherm of the treated zeolite (USY2-AT2+TPA) displayed a similar uptake at lowest relative pressures, indicative of the preservation of the intrinsic zeolite properties. Furthermore, a strongly increased uptake at $p / p_{0}>0.2$ was discerned, which is attributed to the introduced mesoporosity. The total uptake of the aromatic probe molecule was about $5 \mathrm{mmol} \mathrm{g}^{-1}$, i.e. 1.5 -fold that of the untreated USY2 zeolite.

The pyrolysis of low-density polyethylene (LDPE) was investigated as it forms a simple test for diffusion-limited reactions. ${ }^{[38,51,52]}$ Fig. 10b shows the conversion of LDPE $\left(X_{\mathrm{LDPE}}\right)$ to volatile compounds as a function of temperature in presence of USY zeolite catalysts. The conversion profile of USY2-P-H displayed a temperature at which 10\% LDPE is converted $\left(T_{10}\right)$ of $560 \mathrm{~K}$, which is significantly lower than the non-catalyzed degradation of LDPE $\left(T_{10}=710 \mathrm{~K}\right)$. The hierarchical sample (USY2-AT2+TPA-H, $\left.T_{10}=530 \mathrm{~K}\right)$ displayed a catalytic activity significantly higher than the parent zeolite, which is attributed to the more accessible micropore structure. In contrast, USY2-AT2-H evidenced, with a $T_{10}$ of $650 \mathrm{~K}$, a much lower activity than the parent zeolite. This confirms that, upon introducing secondary porosity, the intrinsic zeolite properties should remain mostly preserved. 


\subsection{Strategies for the preparation of hierarchical FAU}

Submitted to

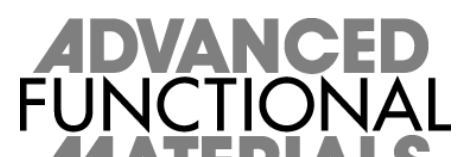

Clearly, the introduction of mesoporosity in Y or USY zeolites by post-synthetic modification requires careful selection of the strategy (Fig. 12). On the one hand, the pristine Al-rich zeolite is highly resistant to alkaline solutions, while on the other hand, the high-Si analogue is extremely sensitive in alkaline media. Hence, the starting zeolite (pristine or steamed) should either be mildly or severely dealuminated, the choice of which should depend on the requirements of the final application. When a mild dealumination is applied, the resulting zeolite should be exposed to a sequential alkaline treatment and acid wash to remove the abundant aluminosilicate debris. In the case of high-Si zeolites, the sequential alkaline treatment should benefit from the inclusion of a pore-growth moderator, e.g. $\mathrm{TPA}^{+}$. Of course, the combination of the two, i.e. both inclusion of pore-growth moderators in the alkaline solution and application of the acid wash, are feasible too.

We expect that the preparation of hierarchical Y and USY zeolites by post-synthetic modifications will have a large impact on catalytic processes associated with bulky reagents and/or fast deactivation. Accordingly, their catalytic superiority in traditional reactions like alkylation, fluid catalytic cracking, and hydrocracking, is expected. Moreover, this novel family of hierarchical faujasites might be promising in the conversion of biomass, since these reactions often take place in viscous aqueous media prone to suffer from diffusional constraints. ${ }^{[3,4]}$

\section{Conclusions}

Combinations of post-synthetic modifications, including base $(\mathrm{NaOH})$ and acid $\left(\mathrm{H}_{4}\right.$ EDTA and $\mathrm{Na}_{2} \mathrm{H}_{2}$ EDTA) treatments, were strategically applied to prepare a wide variety of hierarchical Y and USY zeolites. It was demonstrated that both the pristine Y and its steamed ultra-stable derivative USY need to be carefully dealuminated to facilitate subsequent introduction of 


\section{Submitted to}

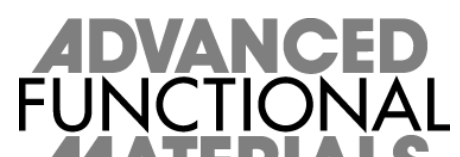

mesoporosity by desilication in alkaline medium. It proved of vital importance to remove Alrich debris after sequential acid and base treatment of $\mathrm{Y}$ and USY zeolites with low Si/Al ratios, freeing porosity, and increasing crystallinity. The sequential alkaline treatment and acid wash concomitantly provides a general strategy to remove amorphous aluminosilicates debris formed after framework dealumination of zeolites. For Al deficient zeolites, the inclusion of $\mathrm{TPA}^{+}$in the alkaline solution plays a vital role moderating Si dissolution, yielding a hierarchical USY zeolite with preserved crystallinity and microporosity. The latter strategy should particularly benefit the introduction of mesoporosity by desilication in zeolites of low framework density and low Al content. The superiority of the hierarchical Y and USY zeolites was conclusively demonstrated in the adsorption of toluene, the alkylation of benzyl alcohol with toluene, and the pyrolysis of LDPE. Our results emphasize that, in principle, each zeolite can be prepared in hierarchical form, provided that both the individual postsynthetic treatments, as well as the sequences hereof, are optimized.

\section{Experimental}

Materials and Procedures: The zeolites used in this study were provided by Zeolyst International, and are derived from the same NaY mother zeolite, i.e. CBV100. As a starting material for the majority of the post-synthetic modifications, zeolite $\mathrm{Y}\left(\mathrm{CBV} 300, \mathrm{NH}_{4}\right.$-form, nominal $\mathrm{Si} / \mathrm{Al}=2.6$ ) was used. This parent (or pristine) sample is coded 'P'. The prefixes 'USY1-', 'USY2-', and 'USY3-’ were used for treatments performed on steamed (CBV500, $\mathrm{NH}_{4}$-form, nominal Si/Al $\left.=2.6\right)$ and severely steamed + dealuminated $(\mathrm{CBV720}, \mathrm{H}-$ form, nominal Si/Al = 15, and CBV760, H-form, nominal Si/Al = 30) USY zeolites, respectively.

Post-synthetic modifications, using aqueous solutions of $\mathrm{H}_{4}$ EDTA, $\mathrm{Na}_{2} \mathrm{H}_{2}$ EDTA, citric acid, $\mathrm{HCl}, \mathrm{NaOH}$, and TPAOH, were performed using the conditions mentioned in Table $\mathbf{1}$ and Table SI1. Treatments using volumes of up to $100 \mathrm{~cm}^{3}$ were performed under magnetic 
Submitted to

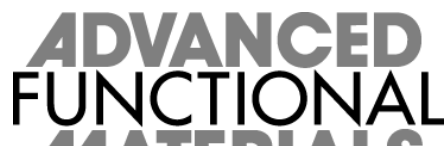

stirring using an Easymax ${ }^{\mathrm{TM}} 102$ instrument from Mettler Toledo. Treatments involving solutions of $100-500 \mathrm{~cm}^{3}$ were executed under magnetic stirring in round-bottomed flasks equipped with reflux condensers. Experiments involving volumes $>500 \mathrm{~cm}^{3}$ were performed in a Büchi miniPilot 5 reactor under mechanical stirring. In a typical experiment, the zeolite sample (0.3-100 g) was added to a vigorously stirred solution of the desired solute, molarity (0.04-5 M), and temperature (338 or $373 \mathrm{~K}$ ), and was left to react for the required time (0.5$72 \mathrm{~h})$. Afterwards, the reaction was quenched and the resulting solid was filtered, washed using distilled water, and dried overnight at $338 \mathrm{~K}$.

Treatments were performed using 6.7 g zeolite per $100 \mathrm{~cm}^{3}\left(\mathrm{H}_{4}\right.$ EDTA and $\mathrm{Na}_{2} \mathrm{H}_{2}$ EDTA), 10 g per $100 \mathrm{~cm}^{3}$ (citric acid), and $3.3 \mathrm{~g}$ per $100 \mathrm{~cm}^{3}(\mathrm{NaOH}$ and $\mathrm{HCl})$. Experiments using $\mathrm{H}_{4}$ EDTA, citric acid, or $\mathrm{HCl}$ were labeled 'DAx' (DA: dealumination). $\mathrm{Na}_{2} \mathrm{H}_{2} \mathrm{EDTA}$ treatments were coded 'AWx' (AW: acid wash). $\mathrm{NaOH}$ treatments were labeled 'ATx' (AT: alkaline treatment), while those involving both $\mathrm{NaOH}$ and TPAOH were named 'AT $x+\mathrm{TPA}$ '. In all cases, the suffix ' $x$ ' represents integers for further specification.

In the case TPAOH was present in the alkaline solution, a calcination in static air at $723 \mathrm{~K}$ for $5 \mathrm{~h}$ using a heating rate $5 \mathrm{~K} \mathrm{~min}^{-1}$ was applied after treatment to remove adsorbed TPA ${ }^{+}$ species. Selected zeolites were brought in the protonic form (code ' $\mathrm{H}$ ') by 3 consecutive ion exchanges in $0.1 \mathrm{M} \mathrm{NH}_{4} \mathrm{NO}_{3}$ (298 K, $8 \mathrm{~h}, 1 \mathrm{~g}$ zeolite per $100 \mathrm{~cm}^{3}$ of solution), followed by the abovementioned calcination protocol. Samples brought to the sodium form, by 3 consecutive ion exchanges in $0.1 \mathrm{M} \mathrm{NaNO}_{3}$ (298 K, $8 \mathrm{~h}, 1 \mathrm{~g}$ zeolite per $100 \mathrm{~cm}^{3}$ of solution), were coded 'Na'.

Characterization: Transmission electron microscopy (TEM) imaging was performed with a Phillips CM12 instrument operated at $100 \mathrm{kV}$. A few droplets of the samples suspended in methanol were placed on a carbon-coated copper grid, followed by evaporation at ambient conditions. Nitrogen adsorption at $77 \mathrm{~K}$ was performed in a Quantachrome Quadrasorb-SI gas 
Submitted to 14 ATE

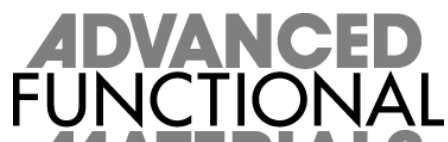

adsorption analyzer. Prior to the measurement, the samples were degassed in vacuum at $573 \mathrm{~K}$ for $3 \mathrm{~h}$. The $t$-plot method was used to discriminate between micro- and mesoporosity. The mesopore size distribution was obtained by the Barrett-Joyner-Halenda (BJH) model applied to the adsorption branch of the isotherm. Mercury intrusion porosimetry experiments were performed on a Micromeritics Autopore IV 9510, which operated in the pressure range from vacuum to 4000 bar. Degassing was undertaken in situ. A contact angle of $140^{\circ}$ for mercury and a cylindrical pore model were used to derive the corresponding pore size distribution. Powder X-ray diffraction (XRD) patterns were acquired in a PANanalytical X'Pert PRO-MPD diffractometer equipped with Bragg-Brentano geometry and Ni-filtered Cu $\mathrm{K} \alpha$ radiation $(\lambda=0.1541 \mathrm{~nm})$. Data were recorded in the $2 \theta$ range of $3-60^{\circ}$ with an angular step size of $0.05^{\circ}$ and a counting time of $8 \mathrm{~s}$ per step. The variation in zeolite crystallinity resulting from post-synthetic modifications was derived from the relative intensity of the (533) reflection at $24^{\circ} 2 \theta$, assuming $100 \%$ crystallinity in the parent sample. The reproducibility of the crystallinity analysis was within 5\%. Si and $\mathrm{Al}$ concentrations in the solids were determined by inductively coupled plasma optical emission spectroscopy (ICPOES) on a Horiba Ultra 2 instrument equipped with photomultiplier tube detection. ${ }^{27} \mathrm{Al}$ magic angle spinning nuclear magnetic resonance (MAS NMR) spectroscopy was performed at a spinning speed of $10 \mathrm{kHz}$ on a Bruker Avance 400 NMR spectrometer equipped with a $4 \mathrm{~mm}$ probe head and $4 \mathrm{~mm} \mathrm{ZrO}_{2}$ rotors at $182.4 \mathrm{MHz}$. Spectra were obtained using 2048 accumulations, 90 pulses with a pulse length of $2.4 \mu \mathrm{s}$, a recycle delay of $0.25 \mathrm{~s}$, and with $\left(\mathrm{NH}_{4}\right) \mathrm{Al}\left(\mathrm{SO}_{4}\right)_{2} \cdot 12 \mathrm{H}_{2} \mathrm{O}$ as a reference. Fourier transform infrared (FTIR) spectroscopy was carried out in a Thermo Nicolet 5700 spectrometer equipped with a SpectraTech Collector II diffuse reflectance (DRIFT) accessory and a high-temperature cell, $\mathrm{KBr}$ windows, and a MCT detector. Spectra were recorded under a $\mathrm{N}_{2}$ atmosphere at $473 \mathrm{~K}$, in the range of $650-4000 \mathrm{~cm}^{-1}$, by co-addition of 200 scans and with a nominal resolution of $4 \mathrm{~cm}^{-1}$. Prior to 
Submitted to

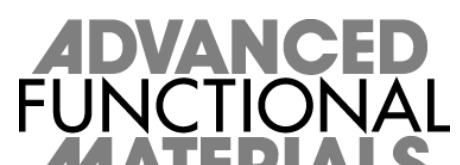

the measurement, the samples were dried at $573 \mathrm{~K}$ in $\mathrm{N}_{2}$ flow $\left(100 \mathrm{~cm}^{3} \mathrm{~min}^{-1}\right)$ for $60 \mathrm{~min}$. Temperature-programmed desorption of ammonia ( $\left.\mathrm{NH}_{3}-\mathrm{TPD}\right)$ was carried out in a Thermo TPDRO 1100 unit equipped with a thermal conductivity detector. The zeolite (100 mg) was pre-treated at $573 \mathrm{~K}$ in He flow $\left(20 \mathrm{~cm}^{3} \mathrm{~min}^{-1}\right)$ for $3 \mathrm{~h}$. Afterwards, $10 \mathrm{vol} . \%$ of $\mathrm{NH}_{3}$ in $\mathrm{He}$ $\left(20 \mathrm{~cm}^{3} \mathrm{~min}^{-1}\right)$ was adsorbed at $473 \mathrm{~K}$ for $30 \mathrm{~min}$ followed by He purging at the same temperature. This procedure was repeated 3 times, after which the desorption of $\mathrm{NH}_{3}$ was monitored in the range of 473-973 $\mathrm{K}$ (heating rate: $10 \mathrm{~K} \mathrm{~min}^{-1}$ ). Adsorption isotherms of toluene were measured at $298 \mathrm{~K}$ in an Intelligent Gravimetric Analyzer (IGA-002, Hiden Analytical). The samples (10 mg) were outgassed at $573 \mathrm{~K}$ for $3 \mathrm{~h}$ prior to measurement. The isotherms were measured by increasing the vapor pressure in the range of 0-38 mbar.

Catalytic testing: The activity of treated zeolites was tested in the liquid-phase alkylation of toluene with benzyl alcohol using an Endeavor ${ }^{\circledR}$ Catalyst System (Argonaut Technologies), consisting of eight parallel reactors with a working volume of $5 \mathrm{~cm}^{3}$ and with continuous stirring by overhead impellers. The catalysts were activated ex situ at $573 \mathrm{~K}$ under inert atmosphere, and maintained at this condition for $1 \mathrm{~h}$ in order to eliminate adsorbed water. Reaction conditions were $T=413 \mathrm{~K}, P=5$ bar, molar toluene-to-benzyl alcohol ratio of 80, and a catalyst amount of 40 wt.\% of zeolite with respect to the amount of benzyl alcohol. Reaction products were analyzed offline at different reaction times using a gas chromatograph (HP 6890) equipped with a mass selective detector (HP 5973). LDPE (Alfa Aesar) pyrolysis was carried out in a Mettler Toledo TGA/DSC 1 STAR $^{\mathrm{e}}$ System. The polymer (6 mg) and the zeolite (2 mg), both in powder form, were carefully weighed in a $70 \mu \mathrm{L} \alpha-\mathrm{Al}_{2} \mathrm{O}_{3}$ crucible and suitably mixed in order to attain an intimate contact. The pyrolysis was performed in $\mathrm{N}_{2}$ $\left(70 \mathrm{~cm}^{3} \mathrm{~min}^{-1}\right.$ ) ramping the temperature from 303 to $973 \mathrm{~K}$ at $10 \mathrm{~K} \mathrm{~min}^{-1}$. 


\section{Acknowledgements}

Submitted to

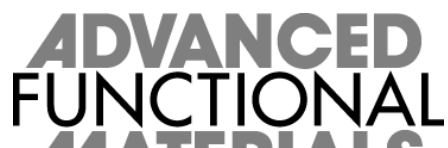

ETH Zurich and the Swiss National Science Foundation (project number 200021-134572) are

acknowledged for financial support. Dr. S. Mitchell and M. Milina are acknowledged for TEM and toluene adsorption analyses, respectively. Supporting Information is available online from Wiley InterScience or from the author.

Received: ((will be filled in by the editorial staff))

Revised: ((will be filled in by the editorial staff)) Published online: ((will be filled in by the editorial staff))

\section{References}

[1] A. Corma, Chem. Rev. 1995, 95, 559.

[2] W. Vermeiren, J. -P. Gilson, Top. Catal. 2009, 52, 1131.

[3] E. Taarning, C. M. Osmundsen, X. Yang, B. Voss, S. I. Andersen, C. H. Christensen, Energy Environ. Sci. 2011, 4, 793.

[4] R. M. West, M. S. Holm, S. Saravanamurugan, J. Xiong, Z. Beversdorf, E. Taarning, C. H. Christensen, J. Catal. 2010, 269, 122.

[5] A. Corma, Chem. Rev. 1997, 97, 2373.

[6] J. Pérez-Ramírez, C. H. Christensen, K. Egeblad, C. H. Christensen, J. C. Groen, Chem. Soc. Rev. 2008, 37, 2530.

[7] S. van Donk, A. H. Janssen, J. H. Bitter, K. P. de Jong, Catal. Rev. -Sci. Eng. 2003, 45, 297.

[8] R. Chal, C. Gerardin, M. Bulut, S. van Donk, ChemCatChem 2011, 3, 67.

[9] S. Lopez-Orozco, A. Inayat, A. Schwab, T. Selvam, W. Schwieger, Adv. Mater. 2011, 23, 2602.

[10] L. Tosheva, V. Valtchev, Chem. Mater. 2005, 17, 2494.

[11] W. J. Roth, J. Čejka, Catal. Sci. Technol. 2011, 1, 43. 
Submitted to

[12] J. Čejka, S. Mintova, Catal. Rev. -Sci. Eng. 2007, 49, 457.

[13] K. Egeblad, C. H. Christensen, M. Yu. Kustova, C. H. Christensen, Chem. Mater. 2008, 20, 946.

[14] D. Verboekend, J. Pérez-Ramírez, Catal. Sci. Technol. 2011, 1, 879.

[15] M. Choi, H. S. Cho, R. Srivastava, C. Venkatesan, D.-H. Choi, R. Ryoo, Nat. Mater. 2006, 5, 718.

[16] H. Chen, J. Wydra, X. Zhang, P. -S. Lee, Z. Wang, W. Fan, M. Tsapatsis, J. Am. Chem. Soc. 2011, 133, 12390.

[17] F. N. Gu, F. Wei, J. Y. Yang, N. Lin, W. G. Lin, Y. Wang, J. H. Zhu, Chem. Mater. 2010, 22, 2442.

[18] R. Chal, T. Cacciaguerra, S. van Donk, C. Gérardin, Chem. Commun. 2010, 46, 7840.

[19] M. Choi, K. Na, J. Kim, Y. Sakamoto, O. Terasaki, R. Ryoo, Nature 2009, 461, 246.

[20] S. Mintova, N. H. Olson, V. Valtchev, T. Bein, Science 1999, 283, 958.

[21] G. T. Kerr, J. Phys. Chem. 1967, 71, 4155.

[22] C. J. Plank, E. J. Rosinski, US257310, 1966.

[23] R. L. Bedard, in Zeolites in Industrial Separation and Catalysis, Wiley, Weinheim, Germany 2002. pp. 72-73.

[24] T. Tatsumi, in Handbook of Porous Solids, Wiley, Weinheim, Germany 2010. pp. 913920.

[25] C. Baerlocher, L. B. McCusker, Database of Zeolite Structures, http://www.izastructure.org/databases.

[26] H. K. Beyer, in Molecular Sieves, Vol. 3, Springer-Verlag, Berlin, Germany 2002. pp. 208-213. 
Submitted to
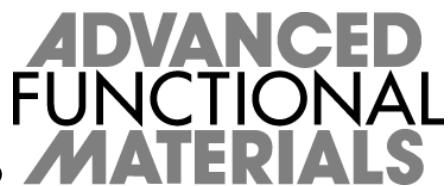

[27] P. Kortunov, S. Vasenkov, J. Kärger, R. Valiullin, P. Gottschalk, M. F. Elía, M. Perez, M. Stöcker, B. Drescher, G. McElhiney, C. Berger, R. Gläser, J. Weitkamp, J. Am. Chem. Soc. 2005, 127, 13055.

[28] A. H. Janssen, A. J. Koster, K. P. de Jong, J. Phys. Chem. 2002, 106, 11905.

[29] J. C. Groen, L. A. A. Peffer, J. A. Moulijn, J. Pérez-Ramírez, J. Mater. Chem. 2006, 16, 2121.

[30] D. Verboekend, J. Pérez-Ramírez, Chem. Eur. J. 2011, 17, 1137.

[31] D. Verboekend, S. Mitchell, M. Milina, J. C. Groen, J. Pérez-Ramírez, J. Phys. Chem. C 2011, 115, 14193.

[32] Z. Qin, B. Shen, X. Gao, F. Lin, B. Wang, C. Xu, J. Catal. 2011, 278, 266.

[33] K. P. de Jong, J. Zečević, H. Friedrich, P. E. de Jongh, M. Bulut, S. van Donk, R. Kenmogne, A. Finiels, V. Hulea, F. Fajula, Angew. Chem. Int. Ed. 2010, 49, 10074.

[34] G. T. Kerr, J. Phys. Chem. 1968, 72, 2594.

[35] A. Gola, B. Rebours, E. Milazzo, J. Lynch, E. Benazzi, S. Lacombe, L. Delevoye, C. Fernandez, Microporous Mesoporous Mater. 2000, 40, 73.

[36] J. Garcia-Martinez, M. M. Johnson, I. Valla, US20100196263, 2010.

[37] C. Fernandez, I. Stan, J. -P. Gilson, K. Thomas, A. Vicente, A. Bonilla, J. PérezRamírez, Chem. Eur. J. 2010, 16, 6224.

[38] D. Verboekend, R. Caicedo-Realpe, A. Bonilla, M. Santiago, J. Pérez-Ramírez, Chem. Mater. 2010, 22, 4679.

[39] D. Verboekend, A. M. Chabaneix, K. Thomas. J. -P. Gilson, J. Pérez-Ramírez, CrystEngComm 2011, 13, 3408.

[40] D. Verboekend, K. Thomas, M. Milina, S. Mitchell, J. Pérez-Ramírez, J. -P. Gilson, Catal. Sci. Technol. 2011, 1, 1331.

[41] A. Corma, C. Martinez, J. E. Doskocil, G. Yaluris, EP2272939, 2011. 
Submitted to

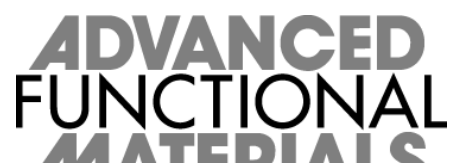

[42] J. C. Groen, J. A. Moulijn, J. Pérez-Ramírez, Ind. Eng. Chem. Res. 2007, 46, 4193.

[43] J. Pérez-Ramírez, S. Mitchell, D. Verboekend, M. Milina, N. -L. Michels, F. Krumeich, N. Marti, M. Erdmann, ChemCatChem 2011, 3, 1731.

[44] G. Kerr, A. W. Chester, D. H. Olson, Catal. Lett. 1994, 25, 401.

[45] B. Sulikowski, J. Datka, B. Gil, J. Ptaszynski, J. Klinowski, J. Phys. Chem. B 1997, $101,6929$.

[46] D. -S. Liu, S. -L. Bao, Q. -H. Xu, Zeolites 1997, 18, 162.

[47] J. C. Groen, S. Brouwer, L. A. A. Peffer, J. Pérez-Ramírez, Part. Part. Syst. Charact. 2006, 23, 101.

[48] B. Xu, F. Rotunno, S. Bordiga, R. Prins, J. A. van Bokhoven, J. Catal. 2006, 241, 66.

[49] V. Calsavara, E. Falabella Sousa-Aguiar, N. R. C. Fernandes Machado, Zeolites 1996, $17,340$.

[50] J. Pérez-Ramírez, D. Verboekend, A. Bonilla, S. Abelló, Adv. Funct. Mater. 2009, 19, 3972.

[51] J. Pérez-Ramírez, S. Abelló, A. Bonilla, J. C. Groen, Adv. Funct. Mater. 2009, 19, 164.

[52] D. Verboekend, J. C. Groen, J. Pérez-Ramírez, Adv. Funct. Mater. 2010, 20, 1441. 


\section{FUNCTIONAD Submitted to 14 A ERIAS}

Figure 1. Transmission electron micrographs of Y zeolites at different stages of the treatment sequence. The scale bar applies to all images. The mesopores are typically homogenously distributed and mostly intra-crystalline.

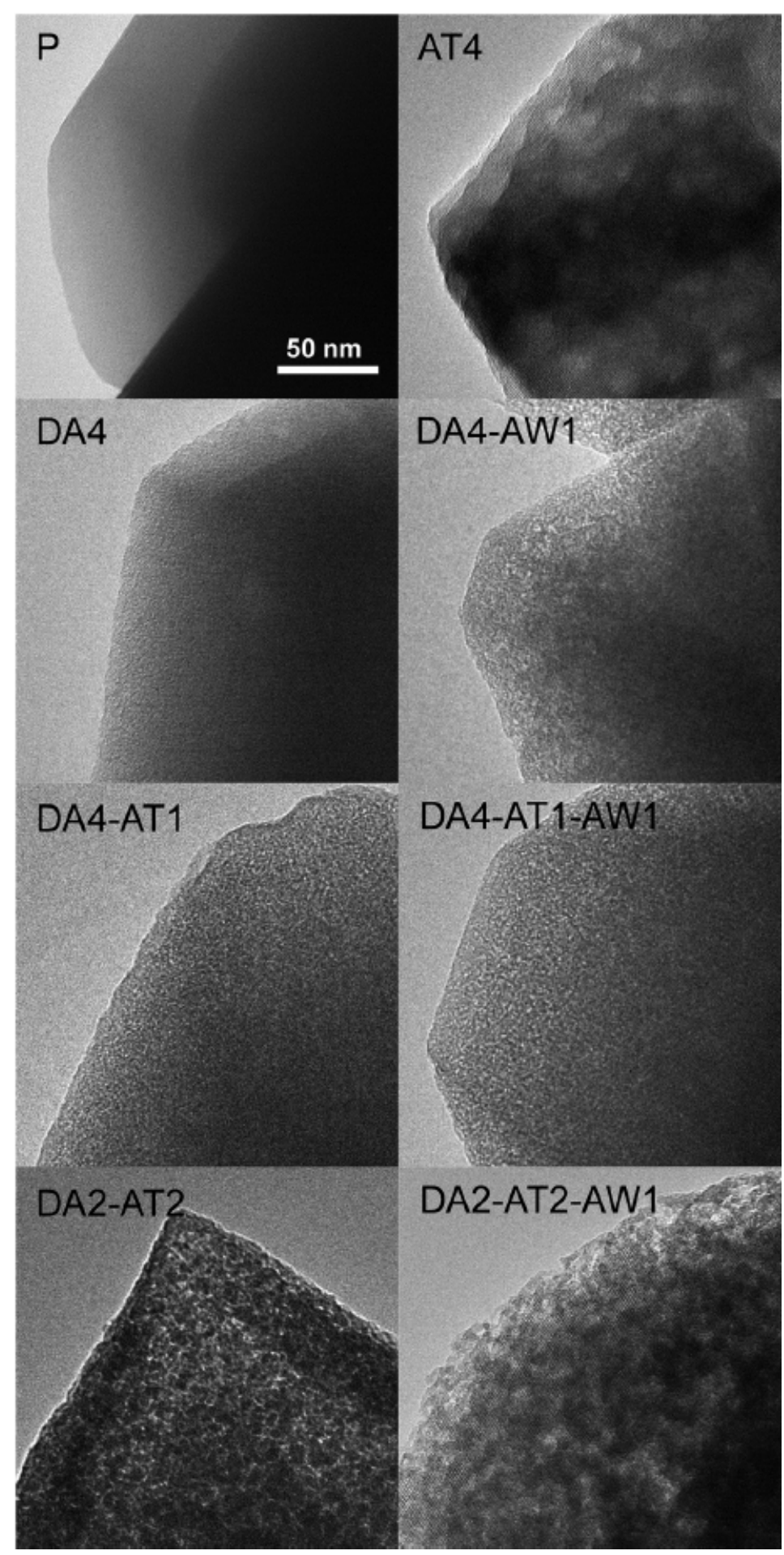




\section{Submitted to

Figure 2. $\mathrm{N}_{2}$ isotherms at $77 \mathrm{~K}$ of $\mathrm{Y}$ zeolites after individual treatment with $\mathrm{NaOH}$ (AT4), $\mathrm{H}_{4}$ EDTA (DA2), and $\mathrm{Na}_{2} \mathrm{H}_{2}$ EDTA (AW1). The inset highlights the uptake at low relative pressures. The individual treatments did not yield Y zeolites with significant mesoporosity.

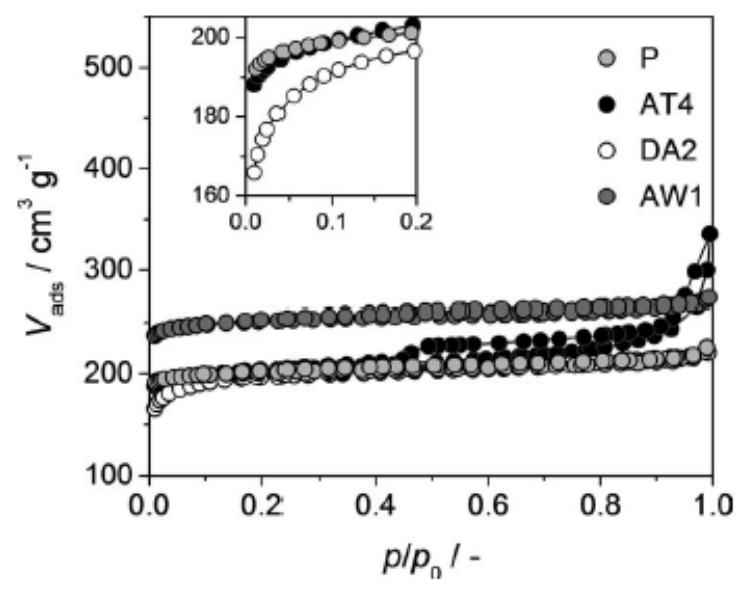




\section{Submitted to

Figure 3. Influence of $\mathrm{NaOH}$ (a), $\mathrm{H}_{4}$ EDTA (b), or $\mathrm{Na}_{2} \mathrm{H}_{2}$ EDTA (c) treatments on crystallinity (solid circles), yield (open circles), micropore volume (solid squares), and mesopore surface area (open squares) of the $\mathrm{Y}$ zeolites. The parent $\mathrm{Y}$ zeolite is represented at $0 \mathrm{M}$.

(a)

(b)

(c)

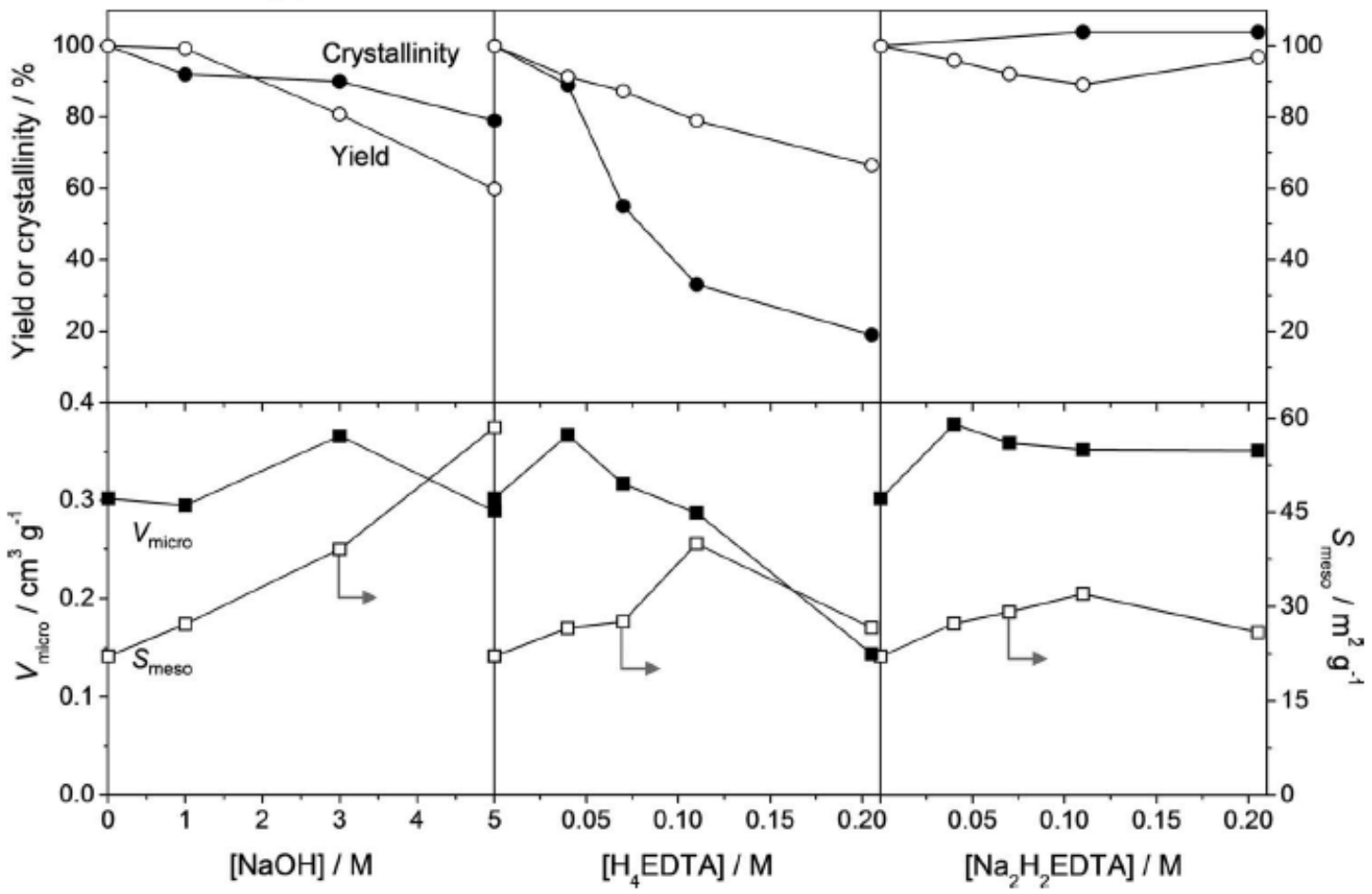




\section{submitted to}

Figure 4. $\mathrm{N}_{2}$ isotherms at $77 \mathrm{~K}$ of the $\mathrm{Y}$ zeolites using different sequences. Insets: $\mathrm{BJH}$ mesopore size distributions. The post-synthetic modifications resulted in hierarchical Y zeolites with distinct mesopore sizes.

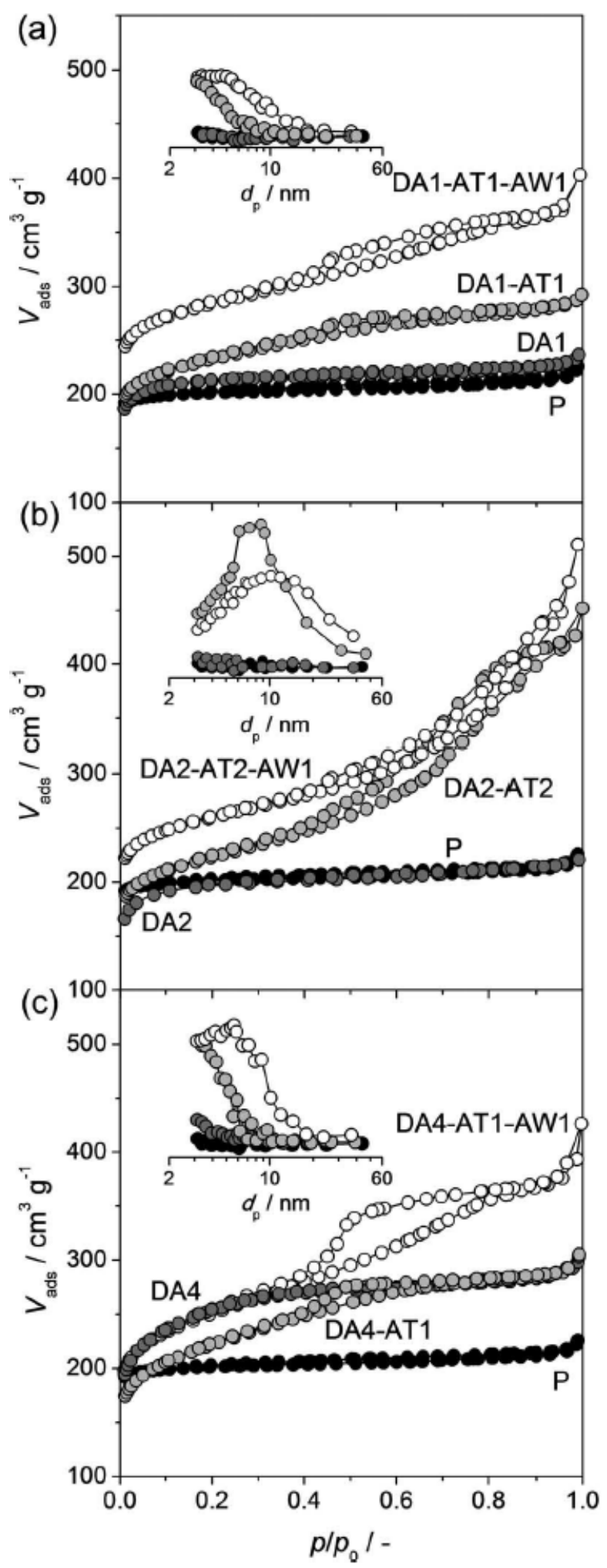




\section{Submitted to

Figure 5. Crystallinity of the $\mathrm{Y}$ zeolites at different stages of the sequential treatments. Dealumination (DA) leads to a significant reduction in crystallinity. However, crystallinity is largely recovered after the final acid wash (AW).

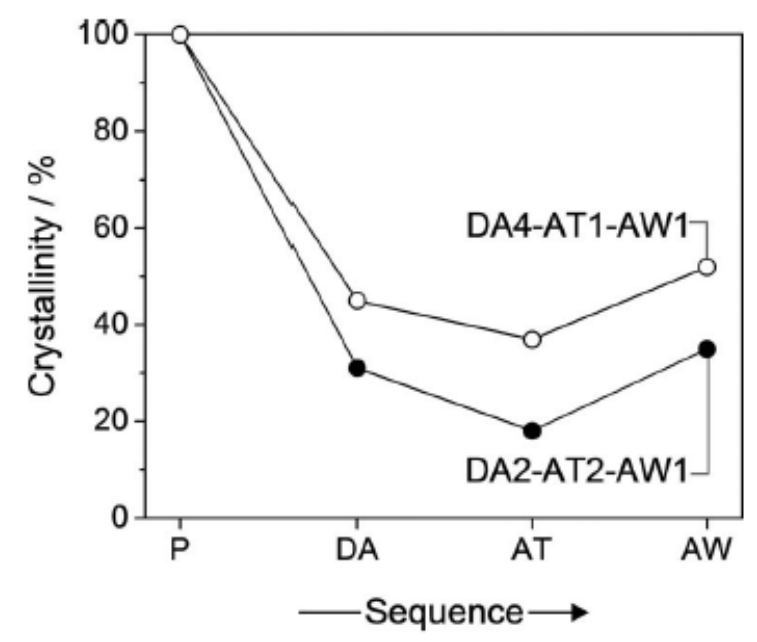




\section{Submitted to}

Figure 6. Contour plots obtained by sequential acid and alkaline treatments of the pristine $\mathrm{Y}$ zeolite. The effects of concentration of $\mathrm{H}_{4}$ EDTA ( $y$-axis) and $\mathrm{NaOH}$ ( $x$-axis) on yield (a), $S_{\text {meso }}(\mathbf{b}), V_{\text {micro }}(\mathbf{c})$, and average mesopore size $\left(d_{\mathrm{p}}\right)(\mathbf{d})$ are depicted. Hierarchical Y zeolites are obtained at $\mathrm{H}_{4}$ EDTA concentrations exceeding $c a .0 .04 \mathrm{M}$.

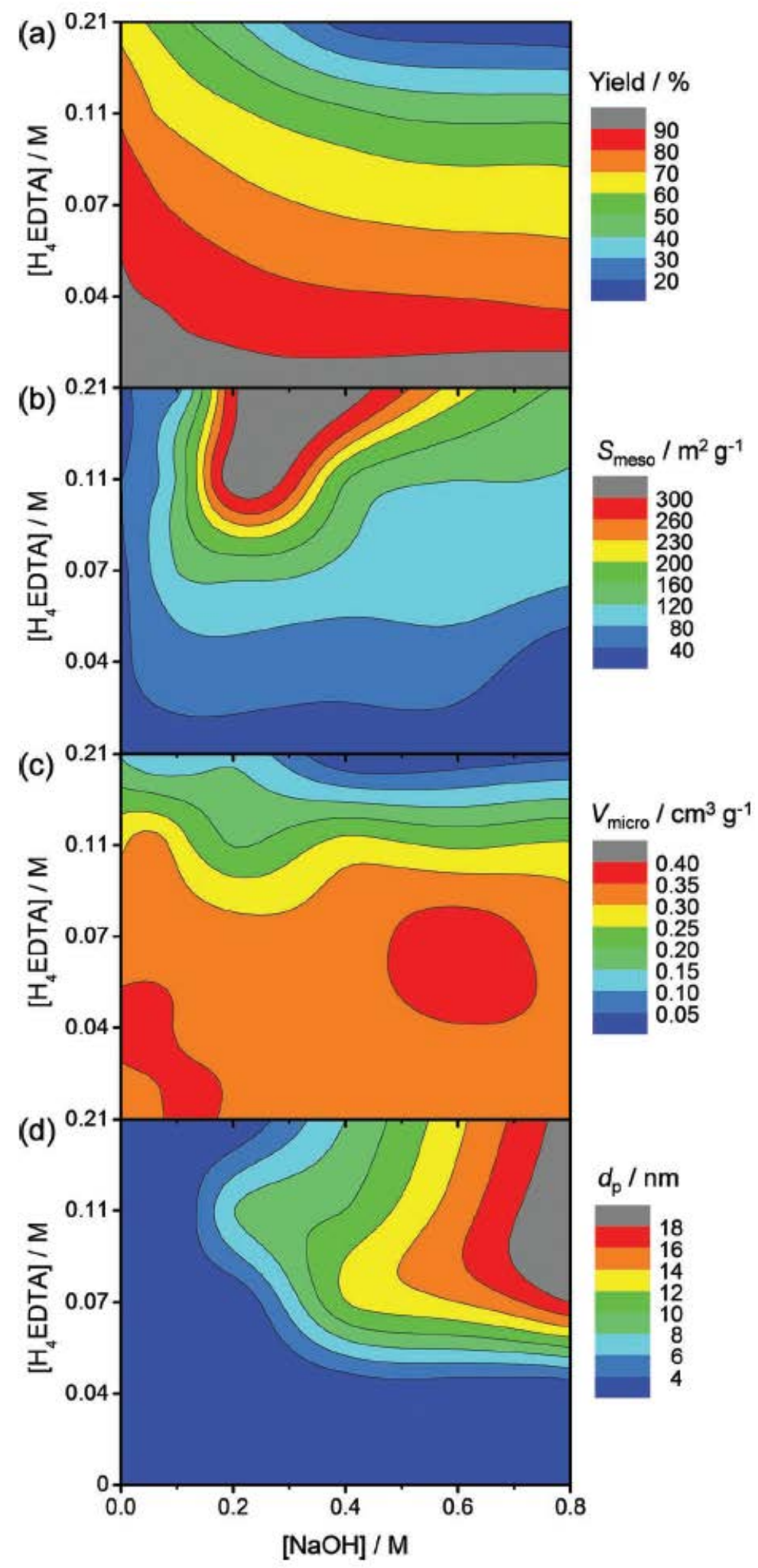




\section{Submitted to

Figure 7. The relation between the average mesopore size $\left(d_{\mathrm{p}}\right)$ and the mesopore surface area ( $\left.S_{\text {meso }}\right)$ of Y zeolites. The sequentially acid and base-treated samples (DA $x$-AT $x$, solid circles), and washed samples (DAx-ATx-AW1, open circles) are derived from Table 2. The parent Y sample is represented by the solid triangle.

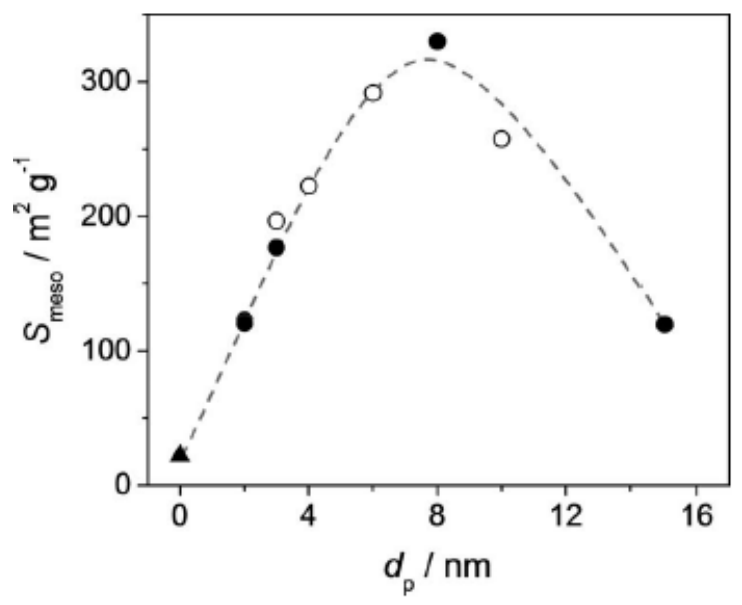




\section{Submitted to \\ FUNCTIONAL}

Figure 8. Infrared spectra in the $\mathrm{OH}$ stretching region of treated $\mathrm{Y}$ zeolites.

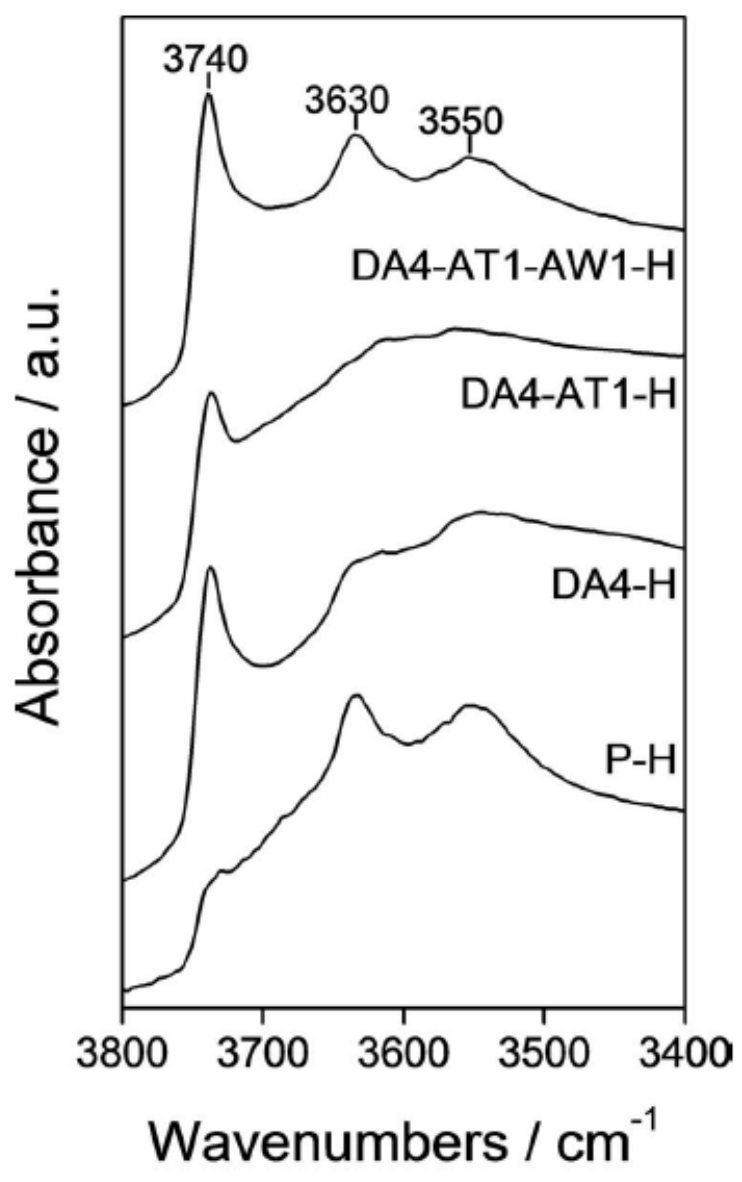




\section{Submitted to

Figure 9. Toluene adsorption isotherms at $298 \mathrm{~K}$ of parent and hierarchical Y and USY zeolites.

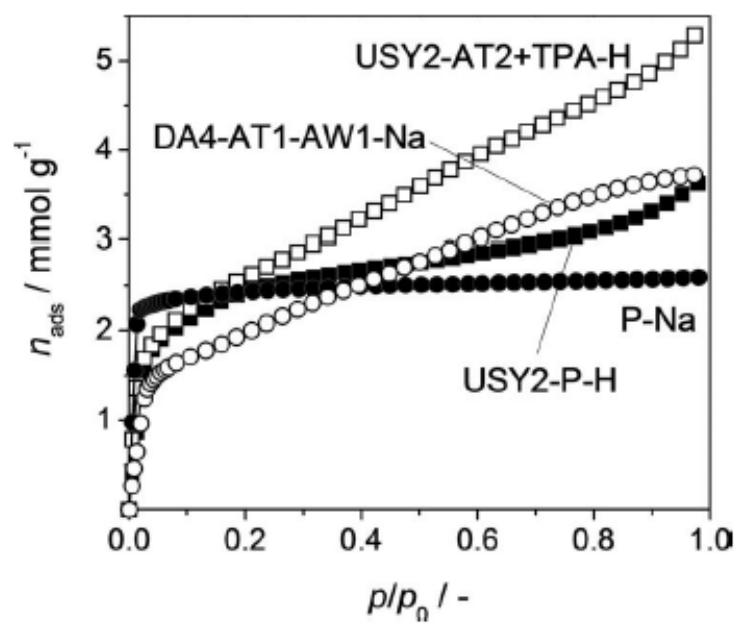




\section{Submitted to \\ FUNCTIONAL \\ MATERIALS}

Figure 10. Catalytic evaluation of $\mathrm{Y}$ and USY zeolites in the alkylation of toluene with benzyl alcohol (a) and the pyrolysis of low-density polyethylene (b). Inset in (b): derivative of the thermo-gravimetric (DTG) profiles. The grey area in the inset highlights the increased light-off activity of sample USY2-AT2+TPA-H.
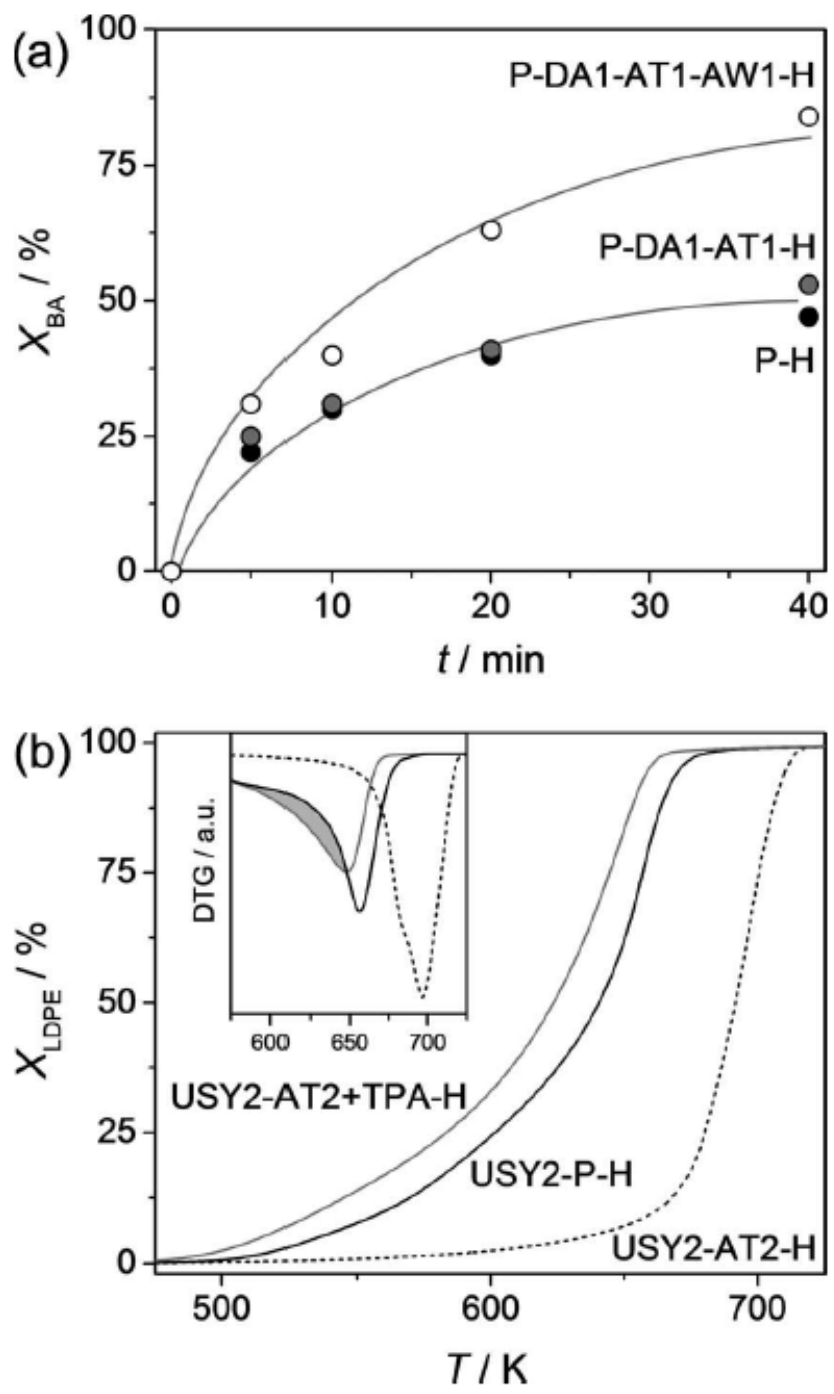


\section{Submitted to \\ FUNCTIONAL \\ MATERIALS}

Figure 11. $\mathrm{N}_{2}$ isotherms at $77 \mathrm{~K}$ (a, c) and transmission electron micrographs (b) of treated Si-rich USY zeolites ('USY2' and 'USY3'). The scale bar in (b) applies to all images. Inset in (a) and (c): BJH mesopore size distributions. The presence of tetrapropylammonium cations (USY2-AT2+TPA, USY3-AT1+TPA, USY3-AT2+TPA) in the $\mathrm{NaOH}$ solution leads to a more controlled zeolite dissolution, and accordingly to the preservation of microporosity and crystallinity upon mesopore formation.

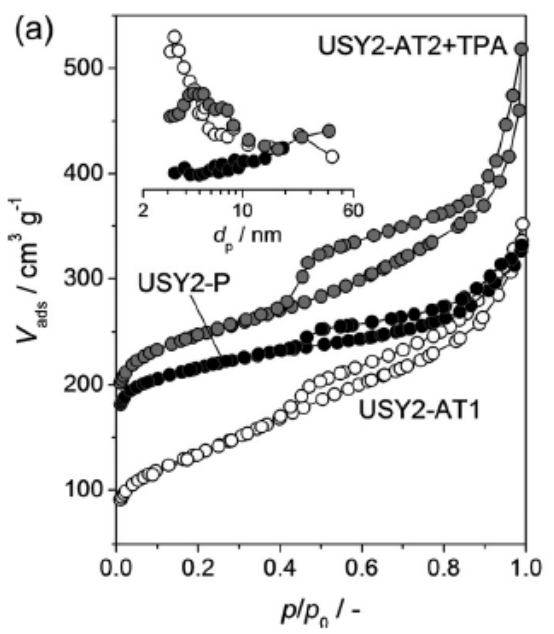

(b)

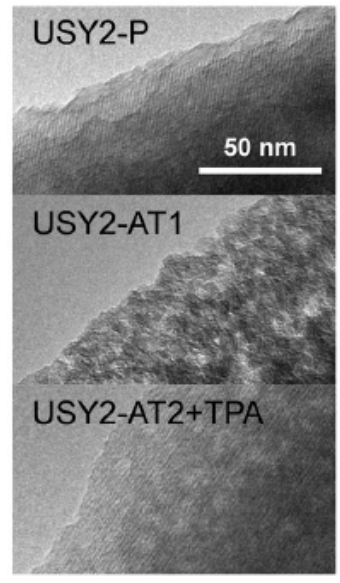

(c)

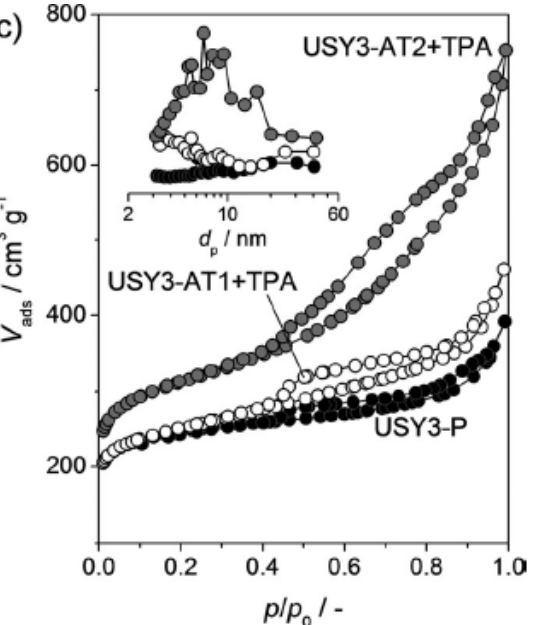




\section{Submitted to

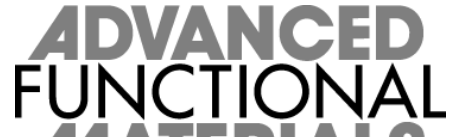

Figure 12. Strategies to design hierarchical FAU zeolites by post-synthetic modifications. After desilication of Al-rich zeolites, the removal of remaining debris by a mild acid wash is crucial. On the other hand, upon alkaline treatment of Si-rich zeolites, the inclusion of poregrowth moderators is highly beneficial.

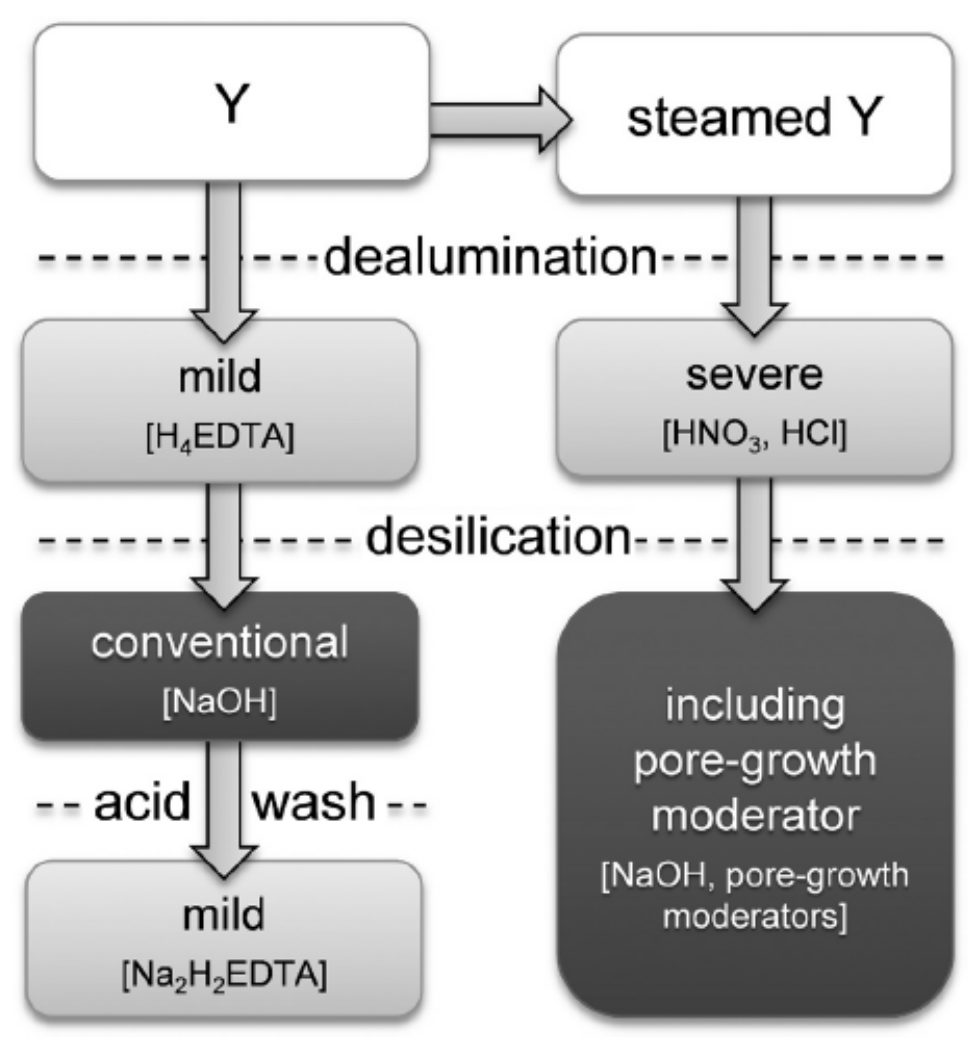




\section{Submitted to

Table 1. Notation of the samples and treatment conditions.

\begin{tabular}{llccc}
\hline Sample code & Reagent & $\begin{array}{c}C \\
{[\mathrm{M}]}\end{array}$ & $\begin{array}{c}T \\
{[\mathrm{~K}]}\end{array}$ & $\begin{array}{c}t \\
{[\mathrm{~h}]}\end{array}$ \\
\hline DA1 & $\mathrm{H}_{4}$ EDTA & 0.07 & 373 & 6 \\
DA2 & $\mathrm{H}_{4}$ EDTA & 0.11 & 373 & 6 \\
DA3 & $\mathrm{H}_{4}$ EDTA & 0.15 & 373 & 6 \\
DA4 & $\mathrm{H}_{4}$ EDTA & 0.11 & 373 & 72 \\
AT1 & $\mathrm{NaOH}$ & 0.10 & 338 & 0.5 \\
AT2 & $\mathrm{NaOH}$ & 0.20 & 338 & 0.5 \\
AT3 & $\mathrm{NaOH}$ & 3.00 & 338 & 0.5 \\
AT4 & $\mathrm{NaOH}$ & 5.00 & 338 & 0.5 \\
AT1+TPA & $\mathrm{NaOH}+\mathrm{TPAOH}$ & $0.05+0.05$ & 338 & 0.5 \\
AT2+TPA & $\mathrm{NaOH}+\mathrm{TPAOH}^{2}$ & $0.15+0.05$ & 338 & 0.5 \\
AW1 & $\mathrm{Na}_{2} \mathrm{H}_{2}$ EDTA & 0.11 & 373 & 6 \\
\hline
\end{tabular}




\section{Submitted to \\ FUNCTIONAL}

Table 2. Yields and physico-chemical properties of Y zeolites.

\begin{tabular}{lccccccc}
\hline Sample & $\begin{array}{c}\text { Yield [a] } \\
{[\%]}\end{array}$ & $\begin{array}{c}\text { Crystallinity [b] } \\
{[\%]}\end{array}$ & $\begin{array}{c}\mathrm{Si} / \mathrm{Al}[\mathrm{c}] \\
{[-]}\end{array}$ & $\begin{array}{c}V_{\text {pore }}[\mathrm{d}] \\
{\left[\mathrm{cm}^{3} \mathrm{~g}^{-1}\right]}\end{array}$ & $\begin{array}{c}V_{\text {micro }}[\mathrm{e}] \\
{\left[\mathrm{cm}^{3} \mathrm{~g}^{-1}\right]}\end{array}$ & $\begin{array}{c}S_{\text {meso }}[\mathrm{e}] \\
{\left[\mathrm{m}^{2} \mathrm{~g}^{-1}\right]}\end{array}$ & $\begin{array}{c}d_{\mathrm{p}}[\mathrm{f}] \\
{[\mathrm{nm}]}\end{array}$ \\
\hline P & - & 100 & 2.4 & 0.34 & 0.30 & 22 & - \\
DA1 & 87 & - & - & 0.36 & 0.32 & 28 & - \\
DA1-AT1 & $91(79)$ & - & - & 0.44 & 0.33 & 121 & 2 \\
DA1-AT1-AW1 & $94(74)$ & - & - & 0.62 & 0.36 & 197 & 3 \\
DA2 & 79 & 31 & - & 0.34 & 0.29 & 40 & - \\
DA2-AT1 & $85(67)$ & - & - & 0.41 & 0.28 & 123 & 2 \\
DA2-AT1-AW1 & $93(62)$ & - & - & 0.47 & 0.23 & 223 & 4 \\
DA2-AT2 & $78(62)$ & 18 & - & 0.66 & 0.20 & 330 & 8 \\
DA2-AT2-AW1 & $87(54)$ & 35 & - & 0.79 & 0.29 & 258 & 10 \\
DA4 & 81 & 45 & 5.5 & 0.46 & 0.36 & 79 & - \\
DA4-AW1 & $89(72)$ & 31 & - & 0.49 & 0.31 & 173 & 3 \\
DA4-AT1 & $89(79)$ & 37 & 3.9 & 0.47 & 0.27 & 177 & 3 \\
DA4-AT1-AW1 & $94(74)$ & 52 & 4.2 & 0.61 & 0.26 & 292 & 6 \\
\hline
\end{tabular}

[a] Individual step yield, in grams of solid after treatment per gram of starting material (overall yield with respect to parent zeolite in brackets). [b] Determined by X-ray diffraction (XRD). [c] Determined by inductively coupled plasma optical emission spectroscopy (ICP-OES). [d] Volume adsorbed at $p / p_{0}=0.99$. [e] $t$-plot method. [f] Average BJH mesopore size. 


\section{Submitted to \\ FUNCTIONAL}

Table 3. Yields and physico-chemical properties of USY zeolites.

\begin{tabular}{lccccc}
\hline Sample & $\begin{array}{c}\text { Yield [a] } \\
{[\%]}\end{array}$ & $\begin{array}{c}\text { Crystallinity [b] } \\
{[\%]}\end{array}$ & $\begin{array}{c}V_{\text {pore }}[\mathrm{c}] \\
{\left[\mathrm{cm}^{3} \mathrm{~g}^{-1}\right]}\end{array}$ & $\begin{array}{c}V_{\text {micro }}[\mathrm{d}] \\
{\left[\mathrm{cm}^{3} \mathrm{~g}^{-1}\right]}\end{array}$ & $\begin{array}{c}S_{\text {meso }}[\mathrm{d}] \\
{\left[\mathrm{m}^{2} \mathrm{~g}^{-1}\right]}\end{array}$ \\
\hline USY1-P & - & 79 & 0.41 & 0.30 & 74 \\
USY1-AT2 & 100 & - & 0.36 & 0.26 & 49 \\
USY1-AT3 & 69 & - & 0.28 & 0.10 & 47 \\
USY1-AT4 & 17 & - & 0.07 & 0 & 12 \\
USY1-DA3 & 84 & 30 & 0.30 & 0.20 & 60 \\
USY1-DA3-AT1 & $64(54)$ & 21 & 0.51 & 0.21 & 214 \\
USY1-DA3-AT1-AW1 & $80(43)$ & 20 & 0.60 & 0.13 & 296 \\
USY2-P & - & 63 & 0.51 & 0.28 & 125 \\
USY2-AT1 & 82 & 24 & 0.52 & 0.10 & 275 \\
USY2-AT2 & 54 & - & 0.28 & 0.04 & 203 \\
USY2-AT1+TPA & 76 & - & 0.58 & 0.28 & 164 \\
USY2-AT2+TPA & 65 & 39 & 0.71 & 0.29 & 253 \\
USY3-P & - & - & 0.61 & 0.33 & 117 \\
USY3-AT1 & 77 & - & 0.47 & 0.05 & 291 \\
USY3-AT2 & 44 & - & 0.58 & 0 & 321 \\
USY3-AT1+TPA & 71 & - & 0.71 & 0.29 & 236 \\
USY3-AT2+TPA & 47 & - & 1.10 & 0.26 & 500 \\
\hline USY10 & & - & & & 0.26 \\
\hline
\end{tabular}

[a] Yield in grams of solid after treatment per gram of starting material (overall yield with respect to parent zeolite in brackets). [b] Determined by X-ray diffraction. Values are relative to parent $\mathrm{Y}$ zeolite (P). [d] Volume adsorbed at $p / p_{0}=0.99$. [d] $t$-plot method. 


\section{Submitted to

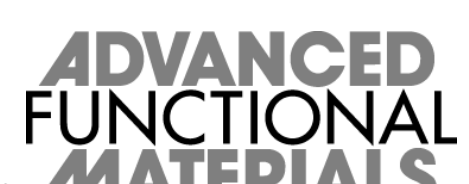

We present strategic combinations of acid and base treatments to design a broad family of hierarchical Y and USY zeolites. The selection of different starting zeolites combined with a comprehensive set of post-synthetic modifications enabled to substantiate the contradictory relationship between the sensitive FAU framework and its high Al content. The sorption and catalytic properties of the hierarchical Y and USY zeolites are superior compared to their conventional counterparts.

Keyword: Zeolites; Porous materials; Catalyst

D. Verboekend, G. Vilé, J. Pérez-Ramírez*

Hierarchical Y and USY zeolites designed by post-synthetic strategies

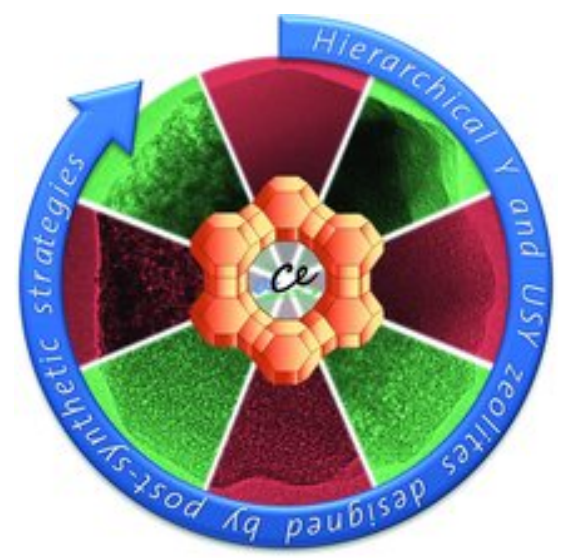


Supporting information

\section{Hierarchical Y and USY zeolites designed by post-synthetic strategies}

Danny Verboekend, Gianvito Vilé, and Javier Pérez-Ramírez

\section{Table of Contents}

\section{Figures}

Figure SI1: X-ray diffraction patterns of Y zeolites.

Figure SI2: Influence of the treatment time during dealumination on crystallinity, microporosity, and mesoporosity of $\mathrm{Y}$ zeolites.

Figure SI3: Hg intrusion curves and pore size distributions of $\mathrm{Y}$ zeolites ........................................

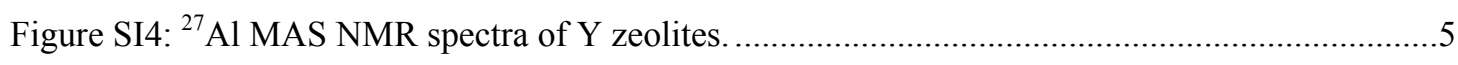

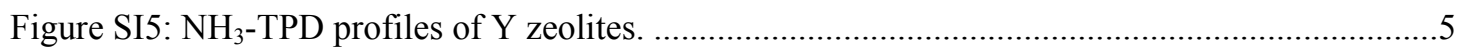

\section{Tables}

Table SI1: Notation of the samples and treatment conditions........................................................

Table SI2: Properties of Y zeolites: Single treatments.......................................................................

Table SI3: Properties of Y zeolites: Acid-washed samples. ................................................................

Table SI4: Properties of Y zeolites: Sequential dealumination-desilication (contour plots). ..............9

Table SI5: Properties of Y zeolites: Dealumination using other acids.............................................. 10

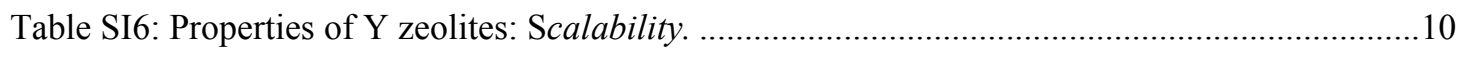

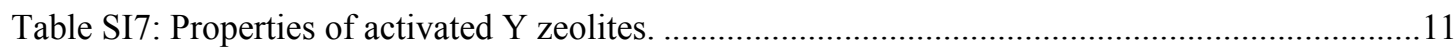




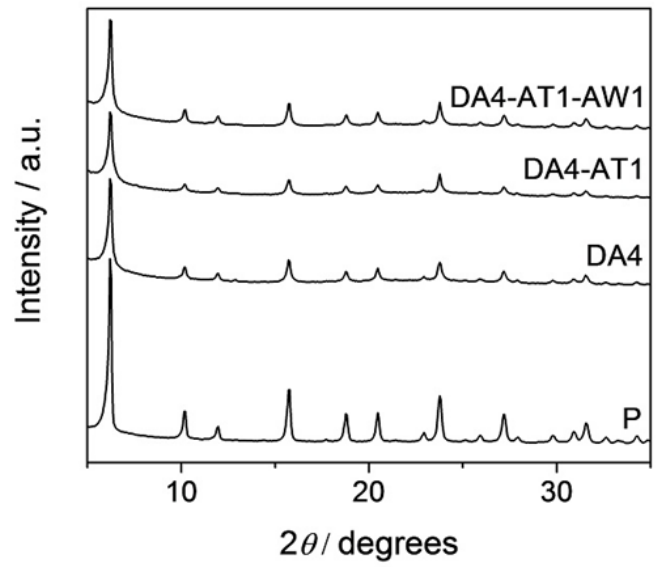

Figure SI1. X-ray diffraction patterns of selected Y zeolites at different stages of the sequential treatment protocol. 

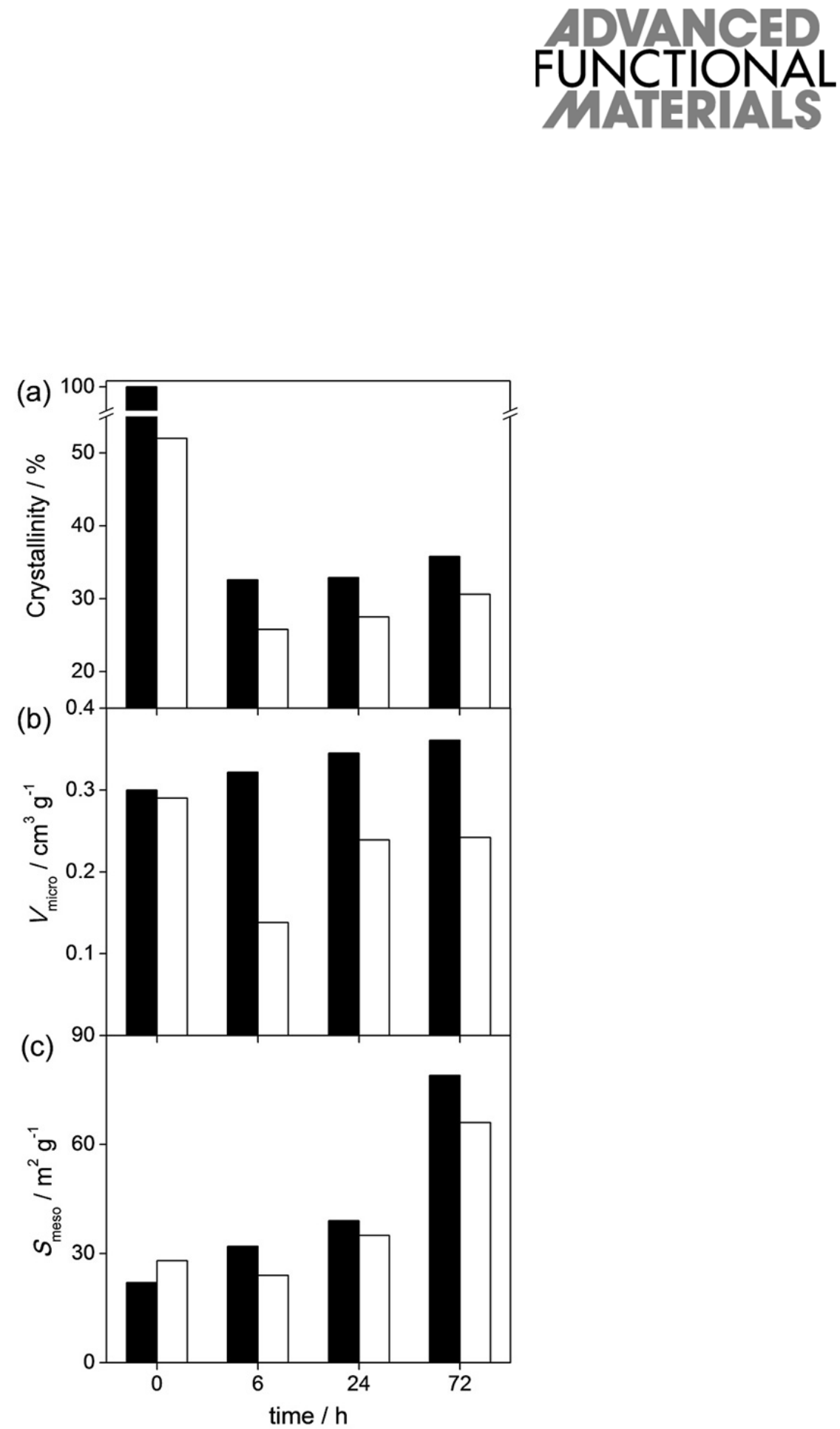

Figure SI2. Influence of the treatment time during dealumination in $0.11 \mathrm{M} \mathrm{H}_{4}$ EDTA at $373 \mathrm{~K}$ on crystallinity (a), microporosity (b), and mesoporosity (c), before (solid bars) and after calcination (open bars). The parent $\mathrm{Y}$ zeolite is represented at $0 \mathrm{~h}$. 
(a)

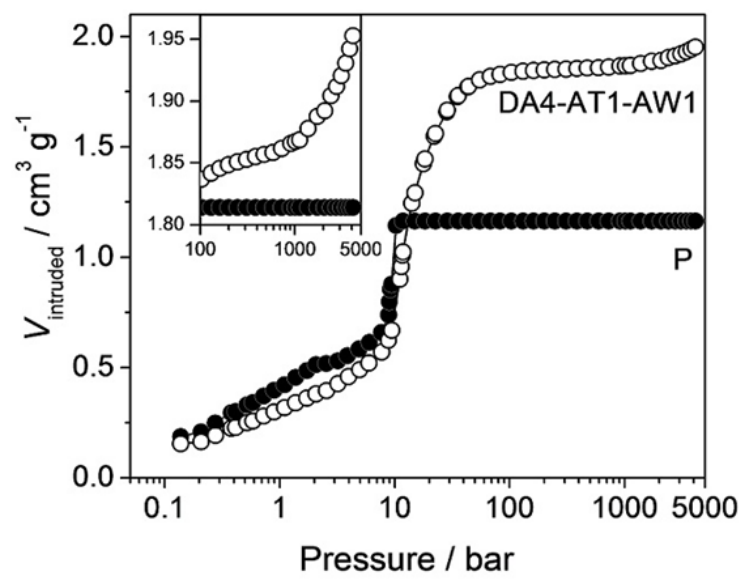

(b)

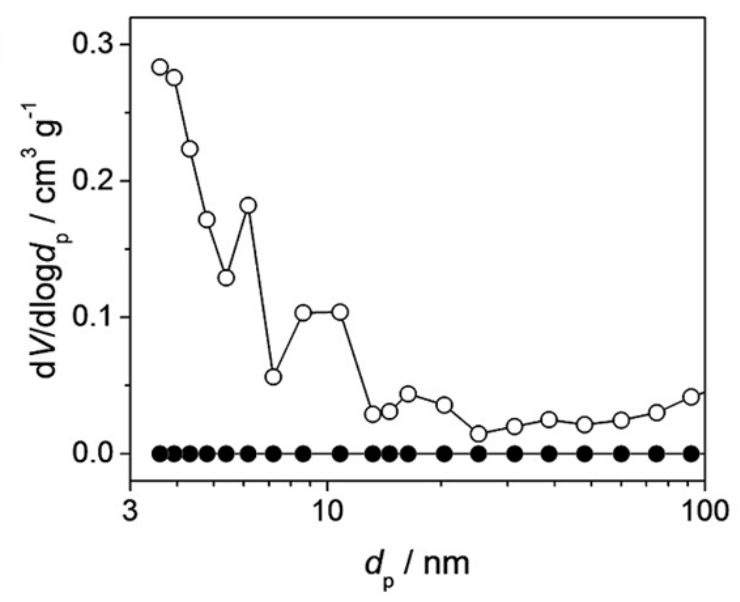

Figure SI3. Hg intrusion curves of Y zeolites (a) and the pore size distributions derived from the Washburn equation (b). The parent $Y$ sample is shifted upwards by $0.65 \mathrm{~cm}^{3} \mathrm{~g}^{-1}$ in the inset. 


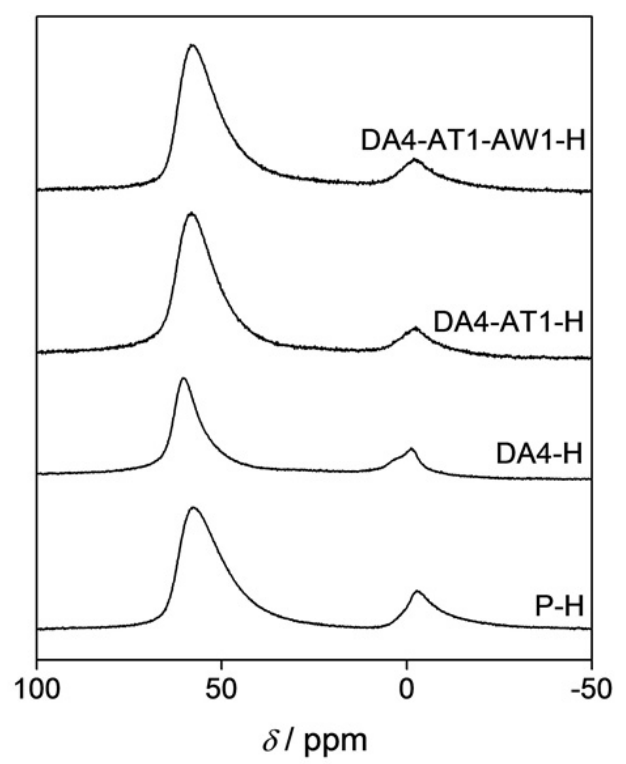

Figure SI4. ${ }^{27}$ Al MAS NMR spectra of Y zeolites at different stages of the sequential treatment protocol.

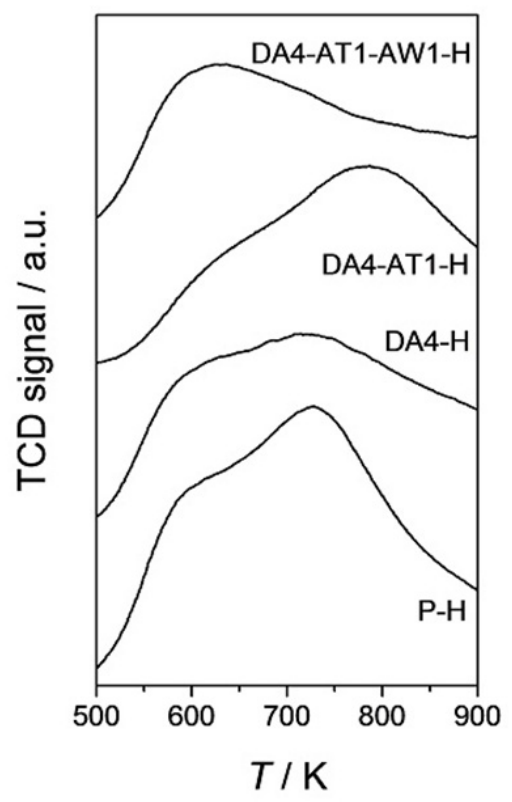

Figure SI5. $\mathrm{NH}_{3}$-TPD profiles $\mathrm{Y}$ zeolites at different stages of the sequential treatment protocol. 
Table SI1. Notation of the samples and treatment conditions.

\begin{tabular}{|c|c|c|c|c|}
\hline Sample code & Reagent & $\begin{array}{c}C \\
{[\mathrm{M}]}\end{array}$ & $\begin{array}{c}T \\
{[\mathrm{~K}]}\end{array}$ & $\begin{array}{c}t \\
{[\mathrm{~h}]}\end{array}$ \\
\hline DA1 & $\mathrm{H}_{4}$ EDTA [a] & 0.07 & 373 & 6 \\
\hline DA2 & $\mathrm{H}_{4}$ EDTA & 0.11 & 373 & 6 \\
\hline DA3 & $\mathrm{H}_{4}$ EDTA & 0.15 & 373 & 6 \\
\hline DA4 & $\mathrm{H}_{4}$ EDTA & 0.11 & 373 & 72 \\
\hline DA5 & $\mathrm{H}_{4}$ EDTA & 0.04 & 373 & 6 \\
\hline DA6 & $\mathrm{H}_{4}$ EDTA & 0.20 & 373 & 6 \\
\hline DA7 & $\mathrm{H}_{4}$ EDTA & 0.11 & 373 & 24 \\
\hline DA8 & $\mathrm{HCl}$ & 0.25 & 338 & 6 \\
\hline DA9 & $\mathrm{HCl}$ & 0.75 & 338 & 6 \\
\hline DA10 & $\mathrm{H}_{3} \mathrm{CA}[\mathrm{b}]$ & 0.1 & 373 & 1 \\
\hline AT1 & $\mathrm{NaOH}$ & 0.1 & 338 & 0.5 \\
\hline AT2 & $\mathrm{NaOH}$ & 0.2 & 338 & 0.5 \\
\hline AT3 & $\mathrm{NaOH}$ & 3.0 & 338 & 0.5 \\
\hline AT4 & $\mathrm{NaOH}$ & 5.0 & 338 & 0.5 \\
\hline AT5 & $\mathrm{NaOH}$ & 1.0 & 338 & 0.5 \\
\hline AT6 & $\mathrm{NaOH}$ & 0.3 & 338 & 0.5 \\
\hline AT7 & $\mathrm{NaOH}$ & 0.4 & 338 & 0.5 \\
\hline AT8 & $\mathrm{NaOH}$ & 0.5 & 338 & 0.5 \\
\hline AT9 & $\mathrm{NaOH}$ & 0.6 & 338 & 0.5 \\
\hline AT10 & $\mathrm{NaOH}$ & 0.8 & 338 & 0.5 \\
\hline $\mathrm{AT} 1+\mathrm{TPA}$ & $\mathrm{NaOH}+\mathrm{TPAOH}[\mathrm{c}]$ & $0.05+0.05$ & 338 & 0.5 \\
\hline $\mathrm{AT} 2+\mathrm{TPA}$ & $\mathrm{NaOH}+\mathrm{TPAOH}$ & $0.15+0.05$ & 338 & 0.5 \\
\hline AW1 & $\mathrm{Na}_{2} \mathrm{H}_{2}$ EDTA [d] & 0.11 & 373 & 6 \\
\hline AW2 & $\mathrm{Na}_{2} \mathrm{H}_{2}$ EDTA & 0.04 & 373 & 6 \\
\hline AW3 & $\mathrm{Na}_{2} \mathrm{H}_{2}$ EDTA & 0.07 & 373 & 6 \\
\hline AW4 & $\mathrm{Na}_{2} \mathrm{H}_{2} \mathrm{EDTA}$ & 0.21 & 373 & 6 \\
\hline AW5 & $\mathrm{Na}_{2} \mathrm{H}_{2}$ EDTA & 0.60 & 373 & 6 \\
\hline
\end{tabular}


Table SI2. Properties of Y zeolites: Single treatments.

\begin{tabular}{lccccc}
\hline Sample code & $\begin{array}{c}\text { Yield [a] } \\
{[\%]}\end{array}$ & $\begin{array}{c}\text { Crystallinity }[\mathrm{b}] \\
{[\%]}\end{array}$ & $\begin{array}{c}V_{\text {pore }}[\mathrm{c}] \\
{\left[\mathrm{cm}^{3} \mathrm{~g}^{-1}\right]}\end{array}$ & $\begin{array}{c}V_{\text {micro }}[\mathrm{d}] \\
{\left[\mathrm{cm}^{3} \mathrm{~g}^{-1}\right]}\end{array}$ & $\begin{array}{c}S_{\text {meso }}[\mathrm{d}] \\
{\left[\mathrm{m}^{2} \mathrm{~g}^{-1}\right]}\end{array}$ \\
\hline P & - & 100 & 0.34 & 0.30 & 22 \\
AT5 & 99 & 92 & 0.35 & 0.30 & 27 \\
AT3 & 81 & 90 & 0.50 & 0.37 & 39 \\
AT4 & 60 & 79 & 0.46 & 0.29 & 59 \\
DA4 & 91 & 89 & 0.41 & 0.37 & 27 \\
\hline DA1 & 87 & 55 & 0.36 & 0.32 & 28 \\
DA2 & 79 & 33 & 0.34 & 0.29 & 40 \\
DA6 & 66 & 19 & 0.19 & 0.14 & 27 \\
AW2 & 96 & - & 0.42 & 0.38 & 27 \\
AW3 & 92 & - & 0.42 & 0.36 & 29 \\
\hline AW1 & 89 & 104 & 0.41 & 0.35 & 32 \\
AW4 & 97 & 104 & 0.42 & 0.35 & 46 \\
AW5 & 97 & - & 0.42 & 0.37 & 30 \\
\hline
\end{tabular}

[a] Yield in grams of solid after treatment per gram of starting material. [b] Determined by X-ray diffraction. [c] Volume adsorbed at $p / p_{0}=0.99$. [d] $t$-plot method. 


\section{ADVANCED
FUNCTINAL
MATERIALS}

Table SI3. Properties of Y zeolites: Acid-washed samples.

\begin{tabular}{lccccc}
\hline Sample code & $\begin{array}{c}\text { Yield }[\mathrm{a}] \\
{[\%]}\end{array}$ & $\begin{array}{c}V_{\text {pore }}[\mathrm{b}] \\
{\left[\mathrm{cm}^{3} \mathrm{~g}^{-1}\right]}\end{array}$ & $\begin{array}{c}V_{\text {micro }}[\mathrm{c}] \\
{\left[\mathrm{cm}^{3} \mathrm{~g}^{-1}\right]}\end{array}$ & $\begin{array}{c}S_{\text {meso }}[\mathrm{c}] \\
{\left[\mathrm{m}^{2} \mathrm{~g}^{-1}\right]}\end{array}$ & $\begin{array}{c}d_{\mathrm{p}}[\mathrm{d}] \\
{[\mathrm{nm}]}\end{array}$ \\
\hline P & - & 0.34 & 0.30 & 22 & - \\
AT4 & 60 & 0.46 & 0.29 & 59 & - \\
AT4-AW1 & $92(55)$ & 0.51 & 0.33 & 75 & - \\
DA2 & 79 & 0.34 & 0.29 & 40 & - \\
DA2-AW1 & $89(71)$ & 0.37 & 0.22 & 125 & 2 \\
\hline DA4 & 81 & 0.46 & 0.36 & 79 & - \\
DA4-AW1 & $89(72)$ & 0.49 & 0.31 & 173 & 3 \\
DA2-AT1 & $85(67)$ & 0.41 & 0.28 & 123 & 2 \\
DA2-AT1-AW2 & $93(63)$ & 0.48 & 0.24 & 209 & 4 \\
DA2-AT1-AW3 & $93(63)$ & 0.61 & 0.29 & 250 & 4 \\
\hline DA2-AT1-AW1 & $92(62)$ & 0.47 & 0.23 & 223 & 4 \\
DA2-AT2 & $78(62)$ & 0.66 & 0.20 & 330 & 8 \\
DA2-AT2-AW2 & $88(55)$ & 0.64 & 0.25 & 215 & 10 \\
DA2-AT2-AW3 & $87(54)$ & 0.63 & 0.23 & 211 & 10 \\
DA2-AT2-AW1 & $87(54)$ & 0.79 & 0.29 & 258 & 10 \\
\hline DA2-AT7 & $66(52)$ & 0.59 & 0.27 & 161 & 8 \\
DA2-AT7-AW2 & $87(46)$ & 0.64 & 0.30 & 185 & 8 \\
DA2-AT7-AW3 & $86(45)$ & 0.65 & 0.27 & 189 & 10 \\
DA2-AT7-AW1 & $85(44)$ & 0.68 & 0.29 & 188 & 10 \\
\hline
\end{tabular}

[a] Individual step yield, in grams of solid after treatment per gram of starting material (overall yield with respect to parent zeolite in brackets). [b] Volume adsorbed at $p / p_{0}$ $=0.99$. [c] $t$-plot method. [d] Average BJH mesopore size. 


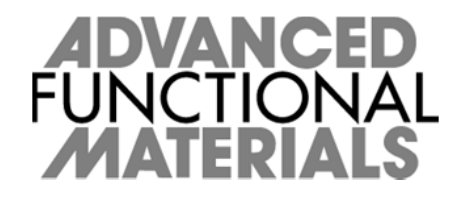

Table SI4. Properties of Y zeolites: Sequential dealumination-desilication (contour plots).

\begin{tabular}{lccccc}
\hline Sample code & $\begin{array}{c}\text { Yield }[\mathrm{a}] \\
{[\%]}\end{array}$ & $\begin{array}{c}V_{\text {pore }}[\mathrm{b}] \\
{\left[\mathrm{cm}^{3} \mathrm{~g}^{-1}\right]}\end{array}$ & $\begin{array}{c}V_{\text {micro }}[\mathrm{c}] \\
{\left[\mathrm{cm}^{3} \mathrm{~g}^{-1}\right]}\end{array}$ & $\begin{array}{c}S_{\text {meso }}[\mathrm{c}] \\
{\left[\mathrm{m}^{2} \mathrm{~g}^{-1}\right]}\end{array}$ & $\begin{array}{c}d_{\mathrm{p}}[\mathrm{d}] \\
{[\mathrm{nm}]}\end{array}$ \\
\hline P & - & 0.34 & 0.30 & 22 & - \\
DA5-AT1 & $97(89)$ & 0.43 & 0.34 & 63 & - \\
DA5-AT2 & $93(85)$ & 0.47 & 0.34 & 66 & - \\
DA5-AT7 & $87(81)$ & 0.45 & 0.33 & 55 & - \\
DA5-AT9 & $87(80)$ & 0.45 & 0.35 & 58 & - \\
\hline DA5-AT10 & $85(77)$ & 0.57 & 0.34 & 11 & 2 \\
DA1-AT1 & $90(79)$ & 0.44 & 0.33 & 121 & 2 \\
DA1-AT2 & $84(74)$ & 0.50 & 0.32 & 132 & 2 \\
DA1-AT7 & $78(68)$ & 0.60 & 0.33 & 108 & 12 \\
DA1-AT9 & $76(66)$ & 0.63 & 0.38 & 110 & 14 \\
\hline DA1-AT10 & $76(66)$ & 0.55 & 0.32 & 91 & 18 \\
DA2-AT1 & $85(67)$ & 0.41 & 0.28 & 123 & 2 \\
DA2-AT2 & $79(62)$ & 0.66 & 0.20 & 330 & 8 \\
DA2-AT7 & $66(52)$ & 0.59 & 0.27 & 161 & 10 \\
DA2-AT9 & $60(47)$ & 0.52 & 0.24 & 120 & 15 \\
\hline DA2-AT10 & $59(47)$ & 0.54 & 0.26 & 117 & 20 \\
DA6-AT1 & $79(53)$ & 0.19 & 0.10 & 65 & - \\
DA6-AT2 & $62(41)$ & 0.44 & 0.14 & 289 & 2 \\
DA6-AT7 & $25(16)$ & 0.52 & 0 & 331 & 8 \\
DA6-AT10 & $14(10)$ & 0.46 & 0.04 & 153 & 19 \\
\hline
\end{tabular}

[a] Individual step yield, in grams of solid after treatment per gram of starting material (overall yield with respect to parent zeolite in brackets). [b] Volume adsorbed at $p / p_{0}=0.99$. [c] $t$-plot method. [d] Average BJH mesopore size. 
Table SI5. Properties of Y zeolites: Dealumination using other acids.

\begin{tabular}{lccccc}
\hline Sample code & $\begin{array}{c}\text { Yield }[\mathrm{a}] \\
{[\%]}\end{array}$ & $\begin{array}{c}V_{\text {pore }}[\mathrm{b}] \\
{\left[\mathrm{cm}^{3} \mathrm{~g}^{-1}\right]}\end{array}$ & $\begin{array}{c}V_{\text {micro }}[\mathrm{c}] \\
{\left[\mathrm{cm}^{3} \mathrm{~g}^{-1}\right]}\end{array}$ & $\begin{array}{c}S_{\text {meso }}[\mathrm{c}] \\
{\left[\mathrm{m}^{2} \mathrm{~g}^{-1}\right]}\end{array}$ & $\begin{array}{c}d_{\mathrm{p}}[\mathrm{d}] \\
{[\mathrm{nm}]}\end{array}$ \\
\hline P & - & 0.34 & 0.30 & 22 & - \\
DA8 & 77 & 0.15 & 0.12 & 20 & - \\
DA8-AT7 & $78(59)$ & 0.35 & 0.19 & 111 & 7 \\
DA9 & 73 & 0.04 & 0 & 14 & - \\
DA9-AT7 & $46(33)$ & 0.43 & 0 & 234 & 10 \\
DA10 & 87 & 0.28 & 0.24 & 26 & - \\
DA10-AT2 & $79(69)$ & 0.42 & 0.29 & 71 & - \\
DA10-AT2-AW1 & $90(62)$ & 0.42 & 0.29 & 75 & - \\
\hline
\end{tabular}

[a] Individual step yield, in grams of solid after treatment per gram of starting material (overall yield with respect to parent zeolite in brackets). [b] Volume adsorbed at $p / p_{0}=0.99$. [c] $t$-plot method. [d] Average BJH mesopore size.

Table SI6. Properties of Y zeolites: Scalability.

\begin{tabular}{lcccccc}
\hline Sample code & $\begin{array}{c}\text { Amount [a] } \\
{[\mathrm{g}]}\end{array}$ & $\begin{array}{c}\text { Yield }[\mathrm{b}] \\
{[\%]}\end{array}$ & $\begin{array}{c}V_{\text {pore }}[\mathrm{c}] \\
{\left[\mathrm{cm}^{3} \mathrm{~g}^{-1}\right]}\end{array}$ & $\begin{array}{c}V_{\text {micro }}[\mathrm{d}] \\
{\left[\mathrm{cm}^{3} \mathrm{~g}^{-1}\right]}\end{array}$ & $\begin{array}{c}S_{\text {meso }}[\mathrm{d}] \\
{\left[\mathrm{m}^{2} \mathrm{~g}^{-1}\right]}\end{array}$ & $\begin{array}{c}d_{\mathrm{p}}[\mathrm{e}] \\
{[\mathrm{nm}]}\end{array}$ \\
\hline P & - & - & 0.34 & 0.30 & 22 & - \\
DA7 & 5 & 82 & 0.39 & 0.35 & 39 & - \\
DA7-AT1 & 1 & $89(73)$ & 0.50 & 0.33 & 163 & 2 \\
DA7-AT1-AW1 & 0.3 & $91(66)$ & 0.48 & 0.21 & 288 & 6 \\
DA7 & 100 & 83 & 0.40 & 0.29 & 72 & - \\
DA7-AT1 & 60 & $92(76)$ & 0.50 & 0.29 & 193 & 2 \\
DA7-AT1-AW1 & 40 & $91(69)$ & 0.54 & 0.21 & 267 & 6 \\
\hline
\end{tabular}

[a] Starting amount upon execution of the last mentioned step. [b] Individual step yield, in grams of solid after treatment per gram of starting material (overall yield with respect to parent zeolite in brackets). [c] Volume adsorbed at $p / p_{0}=0.99$. [d] $t$-plot method. [e] Average BJH mesopore size. 
Table SI7. Properties of activated Y zeolites.

\begin{tabular}{lccccc}
\hline Sample code & $\begin{array}{c}\text { Crystallinity [a] } \\
{[\%]}\end{array}$ & $\begin{array}{c}V_{\text {pore }}[\mathrm{b}] \\
{\left[\mathrm{cm}^{3} \mathrm{~g}^{-1}\right]}\end{array}$ & $\begin{array}{c}V_{\text {micro }}[\mathrm{c}] \\
{\left[\mathrm{cm}^{3} \mathrm{~g}^{-1}\right]}\end{array}$ & $\begin{array}{c}S_{\text {meso }}[\mathrm{c}] \\
{\left[\mathrm{m}^{2} \mathrm{~g}^{-1}\right]}\end{array}$ & $\begin{array}{c}d_{\mathrm{p}}[\mathrm{d}] \\
{[\mathrm{nm}]}\end{array}$ \\
\hline P-H & 52 & 0.32 & 0.29 & 28 & - \\
DA4-H & 29 & 0.32 & 0.24 & 66 & - \\
DA4-AT1-H & 28 & 0.40 & 0.22 & 179 & 3 \\
DA4-AT1-AW1-H & 31 & 0.44 & 0.19 & 230 & 6 \\
\hline
\end{tabular}

[a] Determined by X-ray diffraction. [b] Volume adsorbed at $p / p_{0}=0.99$. [c] $t$-plot method. [d] Average BJH mesopore size. 